\title{
YY1 binding within the human HSD3B2 gene intron 1 is required for maximal basal promoter activity: identification of YY1 as the 3ß1-A factor
}

\author{
D M Foti and J K Reichardt'
}

Department of Biochemistry and Molecular Biology, Institute for Genetic Medicine, USC Keck School of Medicine, Los Angeles, California 90033, USA

${ }^{1}$ Department of Preventive Medicine, Institute for Genetic Medicine, USC Keck School of Medicine, Los Angeles, California 90033, USA

(Requests for offprints should be addressed to J K Reichardt; Email: reichard@usc.edu)

\begin{abstract}

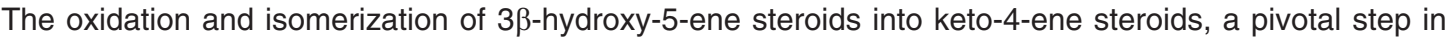
the synthesis of all hormonal steroids, is catalyzed by several isoforms of $3 \beta$-hydroxysteroid dehydrogenase. In humans, two highly homologous isoforms exist, type I expressed by the HSD3B1 gene in peripheral tissues, and type II expressed by the HSD3B2 gene in steroidogenic organs. Previously, it was shown that the HSD3B1 gene 3 31 -A element, encompassing 24 nucleotides of intron 1 not perfectly conserved between the two genes and overlapping with a conserved TG box, contributes to maximal basal promoter activity by binding the ubiquitous and unidentified 3 31 -A transcription factor. In this study for the first time we report that similarly, the HSD3B2 gene intron 1 is required for maximal basal promoter activity in reporter gene analyses, as lack of intron 1 results in a 4- to 10-fold reduction in promoter activity. Mutational analysis in gel shift assays revealed that the $3 \beta 1-\mathrm{A}$ factor binds both the HSD3B2 and HSD3B1 gene intron 1 by requiring only seven nucleotides of a conserved segment within the 3 $31-A$ element. By competition analysis and use of anti-YY1 antibody in both gel shift and Western blot experiments, we identified the 3 31 -A protein as the ubiquitous transcription factor $Y Y 1$. In addition, we have characterized another similar YY1 binding site differently located with respect to the $3 \beta 1-A$ element in both genes. Deletion and mutational analysis in transient transfections experiments revealed that contrarily to as previously shown for the HSD3B1 gene, lack of $Y Y 1$ binding to the type II 3ß1-A element only results in a marginal reduction of basal promoter activity. Instead, YY1 binding to the second site, placed $35 \mathrm{bp}$ downstream from the 3 $\beta 1$-A element, strongly activates the HSD3B2 gene basal promoter activity, as preventing $Y Y 1$ binding to this region caused a 50\% decrease of basal transcription. Complete abrogation of $Y Y 1$ binding within type II intron 1 resulted in a gene reporter activity identical to a reporter construct lacking the whole intron 1. These results designate YY1 as the factor responsible for the intron 1-mediated boost of the HSD3B2 gene basal promoter activity. Similarities and dissimilarities between $Y Y 1$ binding within the HSD3B1 and HSD3B2 gene intron 1 are discussed involving the conserved intron 1 TG box, that suggests different mechanisms are implicated in the YY1-mediated stimulation of these two genes basal promoter activity.
\end{abstract}

Journal of Molecular Endocrinology (2004) 33, 99-119

\section{Introduction}

The enzyme 3 $\beta$-hydroxysteroid dehydrogenase $(3 \beta$-HSD) catalyzes a fundamental step in the synthesis of all hormonal steroids in many tissues and organs (Labrie et al. 1992), which play a crucial role in the differentiation, development, growth, and physiological function of most human tissues. It is also one of the two enzymes that start the degradation of dihydrotestosterone (DHT), the most powerful androgen (Bartsch et al. 1990), thus affecting the availability of this hormone in the regulation of androgen-responsive genes. Two isoforms are known in humans, type I and type II $3 \beta$-HSD, encoded by the HSD3B1 and HSD3B2 gene respectively (Luu-The et al. 1989, Lachance et al. 1990, 1991, Rheaume et al. 1991). The two genes are closely linked on the short arm of 
chromosome 1 (Morrison et al. 1991, Morissette et al. 1995), and both consist of four exons and three introns that have similar length and a high degree of homology (Lachance et al. 1991) (see Fig. 1). Type I and type II $3 \beta$-HSD enzymes are differentially expressed, type II activity being mostly restricted to steroidogenic organs such as ovary, testis and adrenals (Lachance et al. 1991, Rheaume et al. 1991), while type I is found mainly in peripheral tissues, such as placenta, skin, mammary gland, and others (Luu-The et al. 1989, Lachance et al. 1990, 1991, and references therein).

The importance of type II $3 \beta$-HSD activity in steroidogenesis is attested by the many gene mutations resulting in congenital adrenal hyperplasia $(\mathrm{CAH})$, a term that encompasses several recessive autosomal disorders that share the complete or partial deficiency of enzymes involved in corticosteroids synthesis (Levine 2000, White 2001). In both males and females decreased mineralcorticoid secretion results in varying degrees of salt wasting, from lethal to mild phenotypes, and may lead to female masculinization during fetal development. $\mathrm{CAH}$ due to $3 \beta$-HSD type II deficiency may lead to a decrease in all classes of steroid hormones including sex hormones, causing pseudohermaphroditism in males due to gonadal hypospadia (Simard et al. 1993, 2002, Mendonca et al. 1994), and hirsutism, premature pubarche and/or infertility in females (Eldar-Geva et al. 1990, Mendonca et al. 1994, Marui et al. 2000, Pang et al. 2002). Type II $3 \beta$-HSD enzyme has more recently acquired an active role in prostate cancer research (Ross et al. 1998). Androgens are important in the development and maintenance of the prostatic gland (Marker et al. 2003), and it is well documented that they play an important role in the etiology of prostate cancer (Ross \& Shottenfeld 1996, Bosland 2000). Circulating levels of testosterone and DHT are considered indicative of the risk of getting the disease (Gann et al. 1996). Therefore, the ability of the $3 \beta$-HSD activity to degrade DHT has gained interest in the potential mutations or functional sequence variants that may affect the overall enzyme performance, by either altering the enzyme catalytic properties or its expression levels. Interestingly, a study from Chang et al. (2002) has linked both the HSD3B1 and HSD3B2 gene with the susceptibility of sporadic and hereditary prostate cancer.
The recent discovery of a binding site for steroidogenic factor 1 (SF-1) at nucleotide -64 to -56 of the HSD3B2 gene promoter (LeersSucheta et al. 1997), which is not conserved in the HSD3B1 gene, might explain the restricted expression of the HSD3B2 gene to steroidogenic organs. SF-1 had indeed earlier been identified as a tissue-specific transcription factor that regulates all the steroidogenic $P-450$ genes in the adrenal cortex and gonads (Lala et al. 1992, Morohashi et al. 1992). Interestingly, a study by Guerin et al. (1995) identified the $3 \beta 1-\mathrm{A}$ element, a positive regulatory cis-acting element located within the HSD3B 1 gene intron 1 (Fig. 1) that is required for reaching maximal promoter activity in transient transfection assays. This region, encompassing 24 nucleotides protected in DNAse footprinting assay, was shown to strongly bind an unidentified ubiquitously expressed nuclear protein named 3 $\beta 1-\mathrm{A}$ factor, whose molecular mass was estimated as $37 \mathrm{kDa}$ by UV-crosslinking experiments. Mutational analysis revealed that the four Gs that lay at the $3^{\prime}$ end of the protected region, shared with an overlapping TG box (Fig. 1), are essential for binding of the $3 \beta 1-\mathrm{A}$ factor to the regulatory element, and their mutation resulted in a 3- to 6-fold lower expression of a reporter gene. As Spl was found to bind the TG box very weakly, the $3 \beta 1-A$ protein was attributed a transactivator role. Stressing the importance of the $3 \beta 1-\mathrm{A}$ element in enhancing basal transcription, Guerin and collaborators also showed that a double-stranded oligomer bearing the DNA sequence of the HSD3B1 gene $3 \beta 1-\mathrm{A}$ element cloned in front of the mouse pl2 gene promoter was able to stimulate transcription of the CAT reporter gene from 2- to 5-fold in human chorioncarcinoma JEG-3 and human adrenal cortex adenocarcinoma SW-13 cells respectively.

Because of the importance of the type II $3 \beta-H S D$ activity in steroidogenesis, we were prompted to investigate whether or not the HSD3B2 gene intron 1 has any functional relevance, as in the case of the HSD3B1 gene. We here report that intron 1 is required by the upstream promoter of the HSD3B2 gene to achieve the maximal basal level of transcription, as deletion analysis in transient transfection assays revealed that removal of intron 1 results in a drastic reduction of luciferase reporter activity. Despite mismatches in the region, we have ascertained the presence of a $3 \beta 1-A$ element in the HSD3B2 gene intron 1. Furthermore, we have 
identified the $3 \beta 1-\mathrm{A}$ protein to be the multifactorial transcription factor YY1 (Shi et al. 1997), and demonstrate that, in addition to the $3 \beta 1$-A element, YY1 also recognizes a second binding site within intron 1, whose position is not conserved between the two genes. Through mutational analysis and co-expression of YY1 in transfection experiments we were able to correlate YY1 with the boost in basal activity mediated by type II intron 1, and identified the second YY1 binding site, not the $3 \beta 1$-A element, as a major target for YY1-mediated boost of HSD3B2 gene basal promoter activity.

In addition, we provide evidence that Sp3 binds the TG box in the intron 1 of both genes and that the binding efficiency is much higher for the type I TG box. We found the second YY1 binding site in the HSD3B1 gene to be positioned at the $3^{\prime}$ end of the TG box. In in vitro binding conditions, the presence of the weaker YY1 site in such a location appears to favor Sp3 competition for the TG box, thus explaining the stronger Sp3 binding to type I intron 1. Although we have not investigated the functional relevance of those findings for the HSD3B1 gene, our results point to a role for YY1 in the basal expression of $3 \beta$-HSD activity, and suggest that different mechanisms may be involved in the maintenance of the HSD3B1 and HSD3B2 gene basal activity under experimental conditions, as discussed.

\section{Materials and methods}

\section{Plasmid constructions}

The human HSD3B2 gene 5'-flanking and 5'-UTR (from -1265 to +193 ) was amplified by PCR from human genomic DNA isolated from blood using the forward primer 5'-CGGAGGGGTTAATAAA CATTTAAGCGAATAATAAAA- ${ }^{\prime}$ and the reverse primer 5'-GGGGTCGAGACGCAGAAGA GGGCTAAAAAC-3'. The amplification product was digested with Mlul and Xhol and cloned in pGL3Basic (Promega) similarly digested, obtaining $p G L 3-H S D 2(-1253 /+193)$. To obtain the reporter plasmids used in the study, this construct was digested with Sacl and the resulting plasmid re-ligated to generate $p G L 3-H S D 2(-517 /+193)$, or digested with Mlul and PstI, filled in with Klenow at the $5^{\prime}$ end and re-ligated to generate $p G L 3-H S D 2(-217 /+193)$. To generate $p G L 3-H S D 2(-517 /+23)$, the corresponding reporter construct missing the intron 1 sequence, pGL3-HSD2 $(-517 /+193)$ was digested with Drd1 and Xhol, filled in with Klenow and re-ligated. The insert nucleotide sequence was verified by automated DNA sequencing using the forward RV3 primer 5'-CTAGCAAAATAGGCTGT GCG-3', and reverse GL2 primer 5'-CTTTATGT TTTTGGGGTCTTCG-3’ from Promega, which respectively match upstream and downstream to the $p G L 3$ Basic vector multiple cloning site.

\section{Site-directed mutagenesis}

Mutations were introduced into the reporter plasmids using the QuikChange Site-Directed Mutagenesis Kit (Stratagene, La Jolla, CA, USA) following the manufacturer's instructions and using the same mutant oligomers that are represented in the figures that accompany this paper. Mutations were confirmed by DNA automated sequencing (ABI PRISM 3100 Genetic Analyzer; Applied Biosystems, Foster City, CA, USA). Each sequenceconfirmed mutant insert was released with the appropriate cloning restriction endonucleases, and inserted into similarly digested $p G L 3$ Basic, to ensure the plasmid used in transfections did not carry any PCR-induced nucleotide substitutions within the vector backbone.

\section{Gel shift assays}

Crude nuclear extracts were prepared as previously described by Dent \& Latchman (1993). Oligonucleotides for radiolabeled probes and competitor DNAs were obtained from Invitrogen Corporation and Integrated DNA Technologies (Coralville, IA, USA). Appropriate sense and antisense strands were annealed in Tris $10 \mathrm{mM} \mathrm{pH} 8.0$ by heating at $85^{\circ} \mathrm{C}$ for $3 \mathrm{~min}$ and slowly cooling down to $25^{\circ} \mathrm{C}$. Double-stranded oligomeric probes were $5^{\prime}$ end labeled with $\left[\gamma_{-}{ }^{32} \mathrm{P}\right]$ ATP $(5000 \mathrm{Ci} / \mathrm{mmol})$ using T4 polynucleotide kinase (New England Biolabs, Beverly, MA, USA) according to the manufacturer's instructions. Labeled oligomers were separated from unreacted nucleotides by centrifugation through ProbeQuant G-50 Micro Columns (Amersham Biosciences). One, 3 or $5 \mu \mathrm{g}$ nuclear proteins were pre-incubated with $1 \mu \mathrm{g}$ poly $(\mathrm{dI}-\mathrm{dC}) \cdot \operatorname{poly}(\mathrm{dI}-\mathrm{dC})$ (Sigma-Aldrich) in $20 \mu \mathrm{l}$ binding buffer (Hepes $20 \mathrm{mM}$ pH 7.9, KCl $50 \mathrm{mM}$, $\mathrm{MgCl}_{2} 5 \mathrm{mM}$, dithiothreitol $0.5 \mathrm{mM}$, and $4 \%$ glycerol) for $5 \mathrm{~min}$ at room temperature. The 
labeled probes were then added (100 000 c.p.m., approximately $0 \cdot 1-0 \cdot 2 \mathrm{ng}$ ) and complexes were allowed to form at room temperature for $15 \mathrm{~min}$. The binding reactions were loaded onto a $4.5 \%$ non-denaturing polyacrylamide gels containing $2.5 \%$ glycerol and subjected to electrophoresis in $0.5 \times$ TBE buffer at $17-20 \mathrm{~mA}$ for about $3 \mathrm{~h}$ at room temperature. The gel was dried and either autoradiographed overnight with an intensified screen or exposed to a Storage Phosphor Screen (Amersham Biosciences) and analyzed with a STORM 840 densitometer (Molecular Dynamics, Sunnyvale, CA, USA). The specificity of proteinDNA complexes was analyzed by including 100-fold molar excess of homologous or nonhomologous unlabeled competitor DNA into the binding reactions during the pre-incubation step prior to addition of the probe. To identify nuclear factors that bind to the probes, $1 \mu \mathrm{l}$ specific antibody (rabbit polyclonal anti-YY1, sc-1730; rabbit polyclonal anti-Sp3, sc-644 X; rabbit monoclonal anti-Sp1, sc-420 X; anti-Sp2, sc-643 X; Santa Cruz Biotechnology, Santa Cruz, CA, USA) was incubated with the binding mix for $1 \mathrm{~h}$ at $4{ }^{\circ} \mathrm{C}$ before addition of the labeled oligomers.

\section{In vitro transcription/translation assay}

In vitro-translated YY1 was obtained with the TNT T7/T3 Coupled Reticulocyte Lysate System from Promega. To obtain the template DNA plasmid, YY1 cDNA was released from $p C M V$-YY1 (gift of Dr Shi, Harvard University) by digesting with BamHl and Kpnl restriction endonucleases and cloned into $p C M X$-Ll vector similarly digested. The in vitro coupled transcription/translation reaction was carried out following the manufacturer's instructions in the presence of T3 RNA Polymerase and $1 \mu \mathrm{g}$ non-linearized template. The negative controls were obtained performing a similar reaction in the absence of DNA template, or in presence of $1 \mu \mathrm{g} p C M X$-L1 backbone vector.

\section{Acrylamide capture of $3 \beta 2$ oligomer-bound complexes}

Oligo A-3 $\beta 2$, the $3 \beta 2$ upper strand oligonucleotide modified by addition of an Acrydite moiety (Mosaic Technologies, Waltham, MA, USA) at its $5^{\prime}$ prime end was obtained from Integrated DNA Technologies. The procedure was carried out as described to Nelson et al. (2002) with few modifications: $1 \mu \mathrm{M}$ A-3 $\beta 2$ oligo was annealed with the same amount of the unmodified lower strand and incubated with $150 \mu \mathrm{g}$ SW-13 cell nuclear extract or $0.5 \mathrm{mg}$ LNCaP nuclear extract under the same binding conditions herein described for the electrophoretic mobility shift assay (EMSA), scaling up the reaction volume accordingly to the amount of proteins and oligomers. After $15 \mathrm{~min}$ of incubation, the duplex molecules were immobilized to acrylamide as previously described (Kennet et al. 1997) in the $1 \mathrm{~cm}$ large wells of a non-denaturing $4 \cdot 5 \%$ acrylamide gel $(20 \times 20 \mathrm{~cm})$, and the unbound proteins were separated from the bound complexes by electrophoresis under the same conditions used for the EMSAs. The polyacrylamide fragments containing the covalently linked A-3 $\beta 2$ /protein complexes were excised, and the proteins recovered by triturating the band in extraction buffer (Tris $50 \mathrm{mM} \mathrm{pH} \mathrm{7 \cdot 5,} \mathrm{SDS} 0 \cdot 1 \%$, EDTA $0.25 \mathrm{mM}$ and $2 \cdot 5 \%$ glycerol). Samples were kept under rotation overnight at $4{ }^{\circ} \mathrm{C}$. The slurry was filtrated through a $0.22 \mu \mathrm{m}$ Ultrafree-MC Centrifugal Filter Unit and concentrated by a Microcon Gentrifugal Filter Device (Millipore Corporation, Bedford, MA, USA). Typically, about $0.8 \mathrm{ml}$ extraction buffer was reduced to $50 \mu \mathrm{l}$.

\section{Western blot analysis}

Protein concentrations were determined by the BioRad protein assay. Ten micrograms of nuclear proteins from SW-13 and LNCaP cells, and the same amount of isolated A-3 $\beta 2$-bound proteins, along with $10 \mu \mathrm{l}$ in vitro YY1 were diluted with $2 \times$ SDS loading buffer and loaded onto a $12 \%$ pre-cast GeneMate Endurance acrylamide gels (ISC BioExpress, Kaysville, UT, USA). Proteins were transferred to Hybond-P PVDF transfer membrane (Amersham Pharmacia Biotech) by a semi-dry procedure. Blots were probed with the same polyclonal antiserum against YY1 (1:500) or against Sp3 (1:5000) used in the gel shift experiments as primary antibodies, and horseradish peroxidase-conjugated goat anti-rabbit antibodies (sc-2030; Santa Cruz) were used as secondary antibodies. Bands were visualized using the Western blotting Chemiluminescence Luminol Reagent (Santa Cruz Biotechnology, Santa Cruz, CA, USA). Molecular mass standards recognized by the secondary antibody were used (sc-2031; Santa Gruz Biotechnology). 


\section{Cell cultures and transfections}

All medium and sera were provided by Gibco BRL (Life Technology). SW-13 cells were grown in IMEM medium, and LNCaP cells in RPMI medium, both supplemented with 10\% certified fetal bovine serum (FBS), $2 \mathrm{mM}$ glutamine, and 100 $\mathrm{IU} / \mathrm{ml}$ penicillin and $100 \mu \mathrm{g} / \mathrm{ml}$ streptomycin. COS-7 cells were grown in DMEM medium supplemented with 5\% FBS. Cells were maintained at $37{ }^{\circ} \mathrm{C}$ with $5 \% \mathrm{CO}_{2}$. To compare the luciferase reporter activity of plasmids $p G L 3-\mathrm{HSD} 2(-517 /$ $+193)$ and $p G L 3-H S D 2(-517 /+23)$, SW-13 and COS-7 cells were seeded in six-well plates at a density of $6 \times 10^{5}$ cells/well and $1.6 \times 10^{5}$ cells/ well respectively. Sixteen hours later cells were transfected in triplicate wells by adding in each well $3.5 \mu \mathrm{g}$ reporter plasmid, $0.5 \mu \mathrm{g} p C M V \beta \mathrm{Gal}$ and $1 \mu \mathrm{g}$ empty $p C M X$-Ll vector in presence of LipofectAmine 2000 (Invitrogen, Life Science) accordingly to the manufacturer's instructions (a ratio DNA/ LipofectAmine 1:1.5 was used). Cells were harvested $24 \mathrm{~h}$ later, and cell extracts were assayed for the luciferase activity. To test the mutant constructs reported in Fig. 7, SW-13 cells were seeded in 12-well plates at a density of $3 \times 10^{5}$ cells/well and transfected in duplicates with $2 \mu \mathrm{g}$ DNA and $3 \mu \mathrm{l}$ LipofectAmine (1:1.5) per well. When tested alone, reporter plasmids were transfected at the concentration of $1.8 \mu \mathrm{g} /$ well bringing the DNA amount up to $2 \mu \mathrm{g}$ with $0 \cdot 2 \mu \mathrm{g} p C M V \beta \mathrm{Gal}$ to monitor transfection efficiency. Co-transfection experiments with YY1 expression vector were carried out with $1 \mu \mathrm{g} /$ well reporter and 0.5 or $1 \mu \mathrm{g} /$ well of expression plasmid, keeping the DNA amount constant by adding $p C M X$-L1 empty vector. Because of the transcription factor interference with beta-galactosidase expression vs the control samples consisting of reporter plasmid alone, no $p C M V \beta \mathrm{Gal}$ was added in co-transfection experiments, and the luciferase activity was instead normalized for the protein content, when necessary. Luciferase activity was measured for $20 \mathrm{~s}$ in a luminometer using the Luciferase Assay System (Promega).

\section{Results}

\section{The HSD3B2 gene intron 1 is required for sustaining the basal promoter activity}

It was previously shown that deletion of intron 1, but not exon 1, reduced the HSD3B1 gene basal promoter activity from 3- to 6-fold (Guerin et al. 1995). To test whether intron 1 sequences play a similar role in the HSD3B2 gene basal promoter activity, we generated plasmid pGL3-HSD2 $(-517 /+193)$, which expresses the luciferase reporter gene under the control of the HSD3B2 gene sequence from nucleotide -517 to nucleotide +193 , thus encompassing exon 1 and intron 1 , and plasmid pGL3-HSD2 $(-517 /+23)$, which lacks intron 1 (Fig. 1B). As also intended for a study aiming at characterizing polymorphisms that occur within intron 1, which might affect the splicing of the intron, our promoter constructs encompassing the first intron include the conserved splicing portion of the $3^{\prime}$ splice junction with exon 2 up to 12 nucleotides $(+182 /+193)$. By RT-PCR we confirmed that including the first 12 nucleotides of exon 2 results in intron 1 being properly spliced out in COS-7 cells (result not shown). When $p G L 3-H S D 2(-517 /+193)$ and $p G L 3-$ HSD2 $(-517 /+23)$ were compared in transient transfection experiments with $p G L 3$ empty vector as a negative control in SW-13 cells (Fig. 1B), the promoter activity of the construct bearing intron 1 was 23-fold higher than the negative control. The activity of the construct deleted of intron 1 was stimulated only $4 \cdot 5$-fold over the negative control, with a loss of promoter activity as much as $4 \cdot 7$-fold with respect to the promoter activity of the full-length construct. In COS-7, pGL3-HSD2 $(-517 /+193)$ promoter activity was stimulated 8-fold vs control, while the basal promoter activity of the intron-less construct was only stimulated 1-fold (Fig. 1B). In the steroidogenic SW-13 cells, derived from a small-cell carcinoma of the adrenal cortex (Leibovitz et al. 1973), the gene reporter activity was 3- to 4-fold higher than in COS-7 cells, a non-steroidogenic cell line, which is likely due to tissue specificity (Fig. 1B). However, the fact that deletion of intron 1 resulted in a drastic reduction in basal transcription in both steroidogenic and non-steroidogenic cell lines showed that similarly to the HSD3B1 gene the mechanism involved is not strictly tissue-specific.

\section{The HSD3B2 intron 1 contains a 3ß1-A element}

To determine if a region with functional similarities to the HSD3B1 gene 3 $\beta 1-\mathrm{A}$ element might be responsible for the stimulating effect intron 1 demonstrated in transfection experiments, we 
A

3ß1-A Element

TG Box
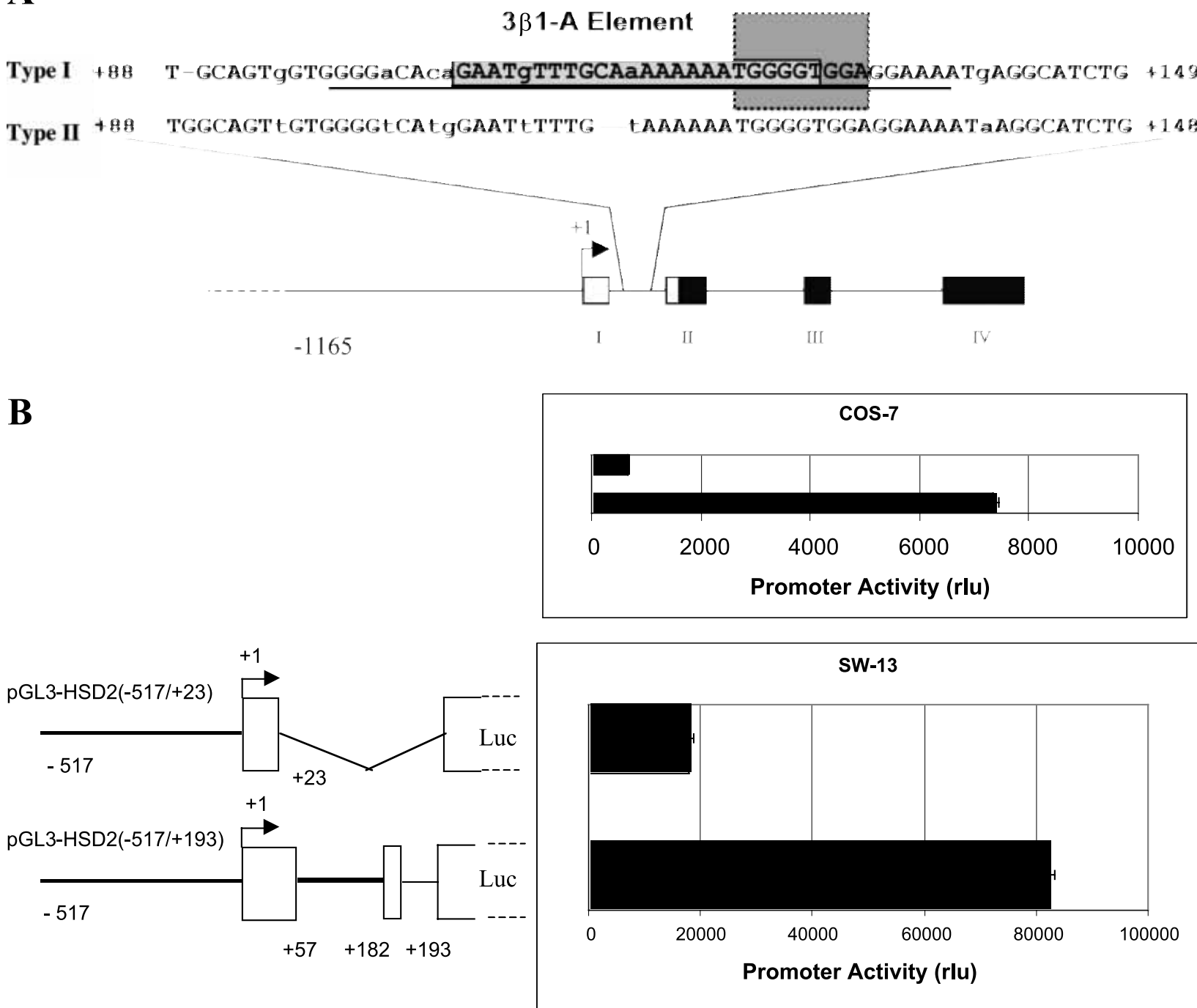

Figure 1 The HSD3B2 gene intron 1 is required for maximal promoter basal activity. (A) A schematic representation of the HSD3B2 gene organization and partial sequence alignment of the HSD3B1 and HSD3B2 intron 1 is shown. Open boxes indicate untranslated exon sequences as well as the 5' and $3^{\prime}$ untranslated regions; solid boxes indicate the coding exons. Roman numbers identify each exon. The transcription initiation start in exon 1 is shown. In the sequence alignment, the nucleotides part of the control elements previously identified in the HSD3B1 gene intron 1 by Guerin et al. (1995) are wrapped by a shaded box and the name of each element is shown above each box. The nucleotides previously identified as protected in DNAse footprinting experiments are underlined. Small letters evidence nucleotide differences between the two aligned sequences. Dotted lines replace missing nucleotides. (B) SW-13 cells $\left(6 \times 10^{5}\right.$ cells/well) and Cos-7 cells $\left(1.6 \times 10^{5}\right.$ cells/well) were seeded in six-well plates and transfected with $p G L 3-H S D 2(-517 /+193)$ and $p G L 3-H S D 2(-517 /+23)$ as described in Materials and Methods. Cells were harvested after $24 \mathrm{~h}$. The promoter activity is reported as relative light units (rlu, luciferase/ $\beta$-galactosidase) as the mean of two independent experiments each performed with duplicate samples, and is expressed as the percentage of control vector $p G L 3$ in SW-13 cells. The standard deviations are shown. A schematic representation of each reporter construct is shown next to the corresponding activity bar. Negative numbers indicate the first nucleotide of the HSD3B2 gene $5^{\prime}$ flanking region included in the construct, positive numbers identify the nucleotidic delimitation of the untranslated regions included in each construct. Open boxes schematize untranslated coding regions. The transcription initiation start $(+1)$ is shown. A straight bold line represent the intron 1 sequence, two interconnected lines indicate deletion of intron 1. 
designed oligo $3 \beta 1$ (Fig. 2C), which matches the HSD3B2 gene intron 1 region corresponding to the $3 \beta 1-\mathrm{A}$ element of the HSD3B1 gene. When tested with nuclear extracts from SW-13, HeLa, COS-7 and LNCaP cells in a gel shift assay, ${ }^{32} \mathrm{P}$-labeled $3 \beta 2$ oligo formed a complex of identical electrophoretic mobility that was competed by 25 -fold molar excess of cold $3 \beta 2$ oligo (Fig. 2A, left panel). When $3 \beta 2$ was compared with $3 \beta 1$, an oligo matching the $3 \beta 1-\mathrm{A}$ element (Fig. $2 \mathrm{C}$ ) as previously explored by Guerin et al. (1995), each probe was shifted into a single major complex of identical intensity and electrophoretic mobility upon incubation with cell nuclear extracts (shown with SW-13 cells in Fig. 2A, middle panel, lanes 1 and $5)$. The complex was competed by 100 -fold molar excess of the same unlabeled oligo (Fig. 2A, middle panel, lanes 2 and 6), but not competed by 100-fold molar excess of an oligo containing the Spl consensus (Fig. 2A, middle panel, lanes 3 and 7), indicating that the protein forming the complex specifically recognizes the probe. Guerin et al. (1995) had previously established that the appearance of the ubiquitous $3 \beta 1-\mathrm{A}$ band requires the integrity of the stretch of four Gs shared by the $3 \beta 1-\mathrm{A}$ element and TG box, as well as the presence of zinc ions in the binding reactions. To find out if the $3 \beta 1-\mathrm{A}$ factor was the protein responsible for the identical mobility complex formed by the $3 \beta 1$ and $3 \beta 2$ probes, we tested two mutant oligos in which the four Gs were replaced with As $(3 \beta 1 \mathrm{~m}$ and $3 \beta 2 \mathrm{~m}$, Fig. 2G) as previously explored by Guerin et al. The two mutant oligos were unable to form the complex when used as a probe (Fig. 2A, middle panel, lanes 4 and 8), which indicates that both the complex formed by $3 \beta 1$ and the complex formed by $3 \beta 2$ require the $\mathrm{G}_{4}$ stretch shared with the overlapping TG box, as expected for the $3 \beta 1-\mathrm{A}$ protein. When the $3 \beta 1$ probe was competed by 100 -fold molar excess of cold Sp1, $3 \beta 2$ and $3 \beta 2 \mathrm{~m}$ oligos, only the competition with $3 \beta 2$ oligo prevented formation of the complex, as seen in Fig. 2A with LNCaP cell nuclear extract to show ubiquity of the $3 \beta 1$ complex (Fig. 2A, right panel, compare lane 4 with lanes 1, 2 and 3). This result indicates that the protein forming the specific complex with $3 \beta 1$ also binds to $3 \beta 2$, and the binding is dependent on the integrity of the $G_{4}$ stretch. To further investigate the authenticity of the complex as the $3 \beta 1-\mathrm{A}$ protein, binding reactions were also performed in presence of
EDTA $10 \mathrm{mM}$ with and without $5 \mathrm{mM} \mathrm{ZnCl}_{2}$. The complex was not formed in presence of EDTA, an ion chelator (Fig. 2A, right panel, lane 5), and it was restored when $\mathrm{Zn}^{2+}$ was added to overcome the EDTA (Fig. 2A, right panel, lane 6), suggesting that the protein forming the complex requires zinc ions to bind the $3 \beta 1$ probe as expected from the $3 \beta 1-\mathrm{A}$ protein. Identical results were obtained when cross-competition of $3 \beta 1$ and $3 \beta 2$ oligonucleotides and $\mathrm{Zn}^{2+}$-dependence were tested with SW-13, COS-7, HeLa, LNCaP and PC-3 cells (not shown). Considered the identical electrophoretic mobility of the single complex formed specifically by $3 \beta 1$ and $3 \beta 2$, considered that both complexes are sensitive to the same changes in the $G_{4}$ stretch as the $3 \beta 1-A$ protein, and that $3 \beta 2$ oligo was able to compete for the $\mathrm{Zn}^{2+}$-dependent band formed by $3 \beta 1$, it is likely that both probes are bound by the same $\mathrm{Zn}^{2+}$-dependent protein. As each probe shifted the same complex from nuclear extracts obtained from several cell lines, which complies with the ubiquity previously observed for the $3 \beta 1-\mathrm{A}$ protein, we conclude that the $3 \beta 1-\mathrm{A}$ protein forms the specific band observed with $3 \beta 1$ and $3 \beta 2$ oligomers. Thus, the HSD3B2 gene intron 1 contains an imperfectly conserved $3 \beta 1$-A element that is still able to bind the $3 \beta 1-\mathrm{A}$ protein, or the $3 \beta 1-A$ protein only binds to a strictly conserved nucleotide segment within this cis-element.

\section{Sp3 binds the TG boxes of type I and type II intron 1 with different efficiency}

The TG box overlapping with the $3 \beta 1$-A element is conserved between type I and type II introns; however, the previous experiment failed to show significant Spl binding to both $3 \beta 1$ and $3 \beta 2$ probe, despite the fact that in the earlier study a weak but more conspicuous Spl binding was observed (Guerin et al. 1995). While the previous study added at both extremities the unrelated sequence gatc, our probe consisted exclusively of nucleotides matching to the region of interest because of a different labeling strategy. Therefore, we reasoned the cause of our undetected Spl binding could be the shorter sequence provided at the $3^{\prime}$ end of our probe and that a probe encompassing more of the TG box $3^{\prime}$ flanking region would provide a better spatial requirement for binding of $\mathrm{Spl}$ family members. For both type I and type II intron sequences, we designed an oligo encompassing fewer 5 ' flanking 

A
SW-13

Probe:

$3 \beta 1 \mathrm{~m}$

Competitor:
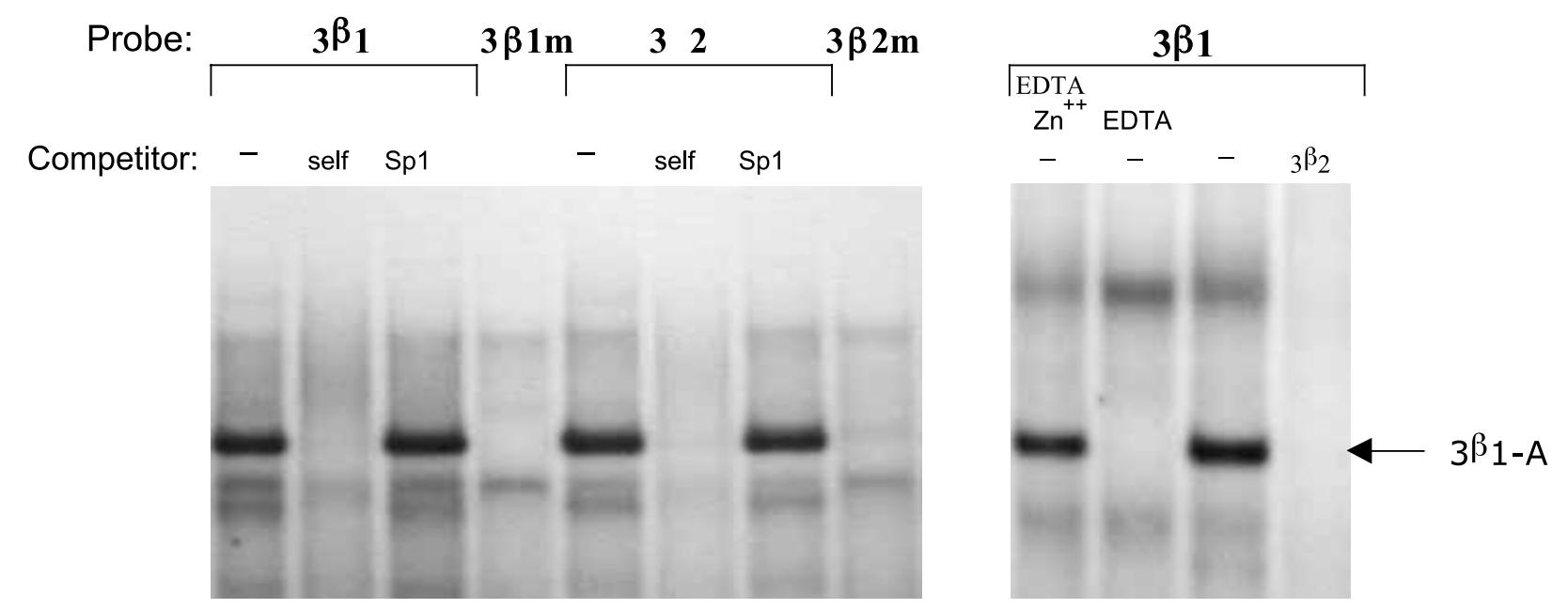

\section{LNCaP}

B

Probe:

$3 \beta 1 S$

$3 \beta 2 S$

Antibody:

Competitor:

self $\quad 3 \beta 2 S \quad$ Sp1 $\quad 3 \beta 1 \quad 3 \beta 2 \quad 3 \beta 1 \mathrm{~m}$

$\alpha \mathrm{Sp} 1 \quad \alpha \mathrm{Sp} 2 \quad \alpha \mathrm{Sp} 3$

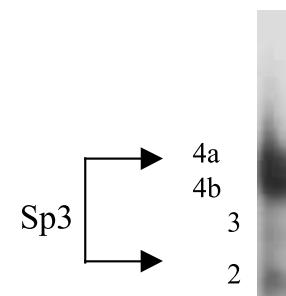

- $\quad$ self $3 \beta 2 \mathrm{~S}$ Spl $3 \beta 1 \quad 3 \beta 2 \quad 3 \beta 1 \mathrm{~m}$
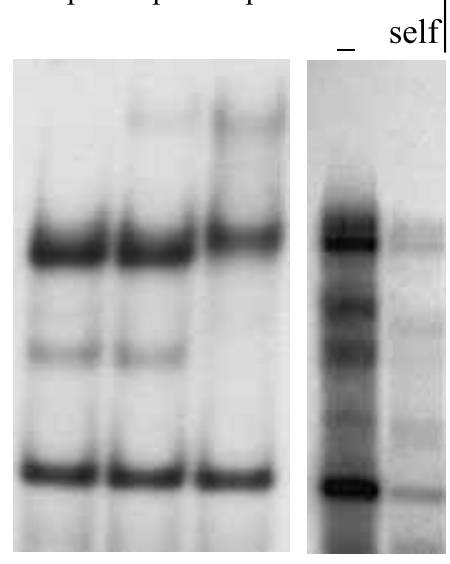

C

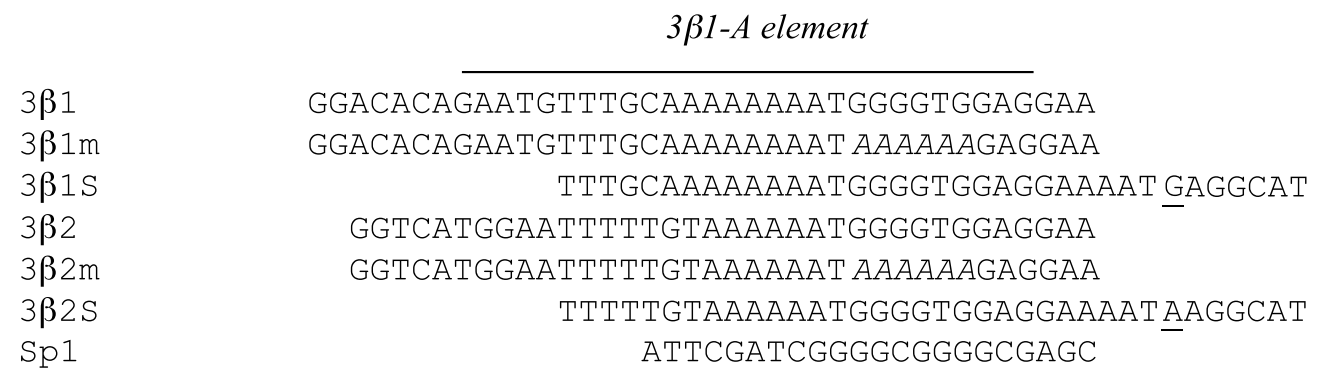


nucleotides and more of the $3^{\prime}$ flanking region when compared with the $3 \beta 1-\mathrm{A}$ element of both genes while maintaining the same length of 36 base pairs ( $3 \beta 1 \mathrm{~S}$ and $3 \beta 2 \mathrm{~S}$, shown in Fig. 2C). Despite lacking a few nucleotides of the $3 \beta 1-\mathrm{A}$ element $5^{\prime}$ prime, these oligos were still able to form the $3 \beta 1-\mathrm{A}$ band in gel shift experiments (Fig. 2B, lanes 1, 11 and 13). In addition, they formed three or four new major complexes of slower electrophoretic mobility, numbered in Fig. 2B after assigning number 1 to the $3 \beta 1-\mathrm{A}$ band. This result matches the four bands previously reported (Guerin et al. 1995), with the difference that the slower mobility band formed by the type I intron 1 specific probe was remarkably more intense, and comparable with the $3 \beta 1-\mathrm{A}$ band (Fig. 2B, lanes 1 and 11). This slower band appeared to be a doublet (named band $4 \mathrm{a}$ and $4 \mathrm{~b}$ ) and was efficiently competed by 100 -fold molar excess of an Spl consensus containing oligonucleotide (Fig. 2B, lane 4), which also competed for band 2. As expected, oligos $3 \beta 1$ and $3 \beta 2$ only partially competed for band 4 and 2 , while efficiently competed out band 1 (Fig. 2B, lanes 5 and 6). Oligo $3 \beta 1 \mathrm{Sm}$, which bears the same substitution $\mathrm{G}_{4}$ to As earlier analyzed in Fig. 2A, not only did not compete for complex 1 as expected, but also for complex 2 and 4 (Fig. 2B, lane 7), indicating that both $\mathrm{Sp} 1$-related and $3 \beta 1-\mathrm{A}$ binding activities rely on the $\mathrm{G}_{4}$ stretch for optimal binding. These mutant oligos did compete the weak complex forming band 3 of intermediate mobility between the Spl consensus competed bands. Such competition suggests a protein binding to the $3 \beta 1-\mathrm{A}$ element in a region not involving the four Gs forms the complex. The use of antibodies against Sp1, Sp2 and Sp3 revealed that Sp3 accounts for two of the three bands competed by $\mathrm{Sp} 1$ consensus. In fact, addition of anti-Sp3 antibody in the binding reactions (Fig. 2B, lane 10) resulted in a significant supershift, as well as in the disappearance of band $4 \mathrm{~b}$, the lower and more conspicuous band of the doublet, and band 2 likely formed by the smaller Sp3 $(73 \mathrm{kDa})$ alternative translation product (Kennett et al. 1997, Suske 1999). Addition of anti-Sp3 antibody also resulted in a darker 4a band, suggesting that Sp3 has the strongest affinity for binding to the region, since only when Sp3 is prevented from binding other factors can access the site. Addition of anti-Spl antibody resulted in disappearance of the fainter upper band (4a) of the doublet and a weak supershift could occasionally be seen (Fig. 2B, lane 8). Addition of anti-Sp2 antibody had the same effect (Fig. 2B, lane 9), with the difference that a slightly more intense supershifted band was seen, with mobility lower than Spl supershift. Surprisingly, the type II intron 1 TG box bound Sp3 less efficiently, as demonstrated by less Sp3 shift when $3 \beta 2 \mathrm{~S}$ oligo was used as a probe (Fig. 2B, compare lane 13 with lane 11 ), and also by its partial ability to compete the doublet formed with labeled $3 \beta 1 \mathrm{~S}$ (Fig. 2B, lane 3). By densitometry analysis we determined that Sp3 binds to the type II TG box 3-fold less than the type I TG box (data not shown). Sp3 binding activity could be brought to the same extent as seen for the type I intron 1 when an oligo bearing a substitution A+136 to G (Fig. 2C) was used (data not shown), which reproduces the $3^{\prime}$ flanking region of the type I TG box. Despite the fact that Sp2 antibody did result in disappearance of the faster band of the doublet, we cannot conclude that Sp2 is part of the observed complex,

\footnotetext{
Figure 2 Identification of a 3ß1-A element in the HSD3B2 gene intron 1. (A) Left: EMSA result obtained when $3 \mu \mathrm{g}$ nuclear extract from the indicated cell lines were incubated with $3 \beta 2$ probe with and without self-competition with 25 -fold molar excess of unlabeled oligo, as described in Materials and methods. Middle: EMSA result obtained when

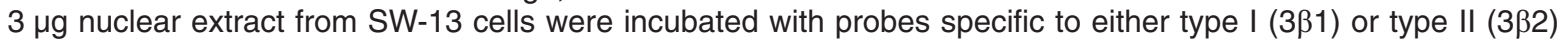
intron, with and without 100-fold molar excess of the indicated competitor oligonucleotides, as described in Materials and methods. - , indicates no competition. Right: $5 \mu \mathrm{g}$ nuclear extracts from LNCaP cells were incubated with $3 \beta 1$ probe in the presence of EDTA $10 \mathrm{mM}$, with and without $5 \mathrm{mM}$ zinc chloride. The competition with 100 -fold molar excess of cold $3 \beta 2,3 \beta 2 \mathrm{~m}$ and Sp1 oligomers is also shown. (B) Left: EMSA result obtained when $3 \mu \mathrm{g}$ nuclear extract from SW-13 cells were incubated with oligo 3ß1S. Competitor oligos were used at 100-fold molar excess. Middle: the same amount of nuclear extracts as above was pre-incubated with anti-Sp1, anti-Sp2 and anti-Sp3 antibodies as described in Materials and methods. Right: a different EMSA experiment compares complexes formed by $3 \beta 1 \mathrm{~S}$ and $3 \beta 2 S$ probes with $3 \mu \mathrm{g}$ nuclear extract from SW-13 cells. (C) The upper nucleotide sequence of the oligomers employed in these gel shift analysis is shown. Oligos are aligned to center the shared regions encompassing the $3 \beta 1-A$ element, evidenced by a line above the $3 \beta 1$ oligo sequence. The outlined nucleotide in $3 \beta 2 S$ and $3 \beta 1 S$ identifies the single nucleotide mismatch at their $3^{\prime}$ end.
} 
as anti-Sp2 antibody was able to supershift Sp1 protein expressed in Drosophila Schneider's cells (not shown), which do not express Spl family members, thus indicating cross-reactivity. No other cross-reactivity was observed in this study.

\section{Mapping the boundaries between 3ß1-A and Sp3 binding activities}

Our EMSA results indicated that $3 \beta 1-\mathrm{A}$ and Sp3

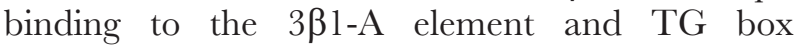
respectively are mutually exclusive, as no lower mobility complex indicative of a protein-protein interaction could be seen. Therefore, we were interested in creating mutants able to bind either the $3 \beta 1-\mathrm{A}$ protein or Sp3 to be able to discern the function of each of those two factors in relation to the HSD3B2 gene basal promoter activity upon transfection experiments. To precisely define how and at what extent the $\mathrm{G}_{4}$ stretch is shared between the apparently overlapping cis-elements, we compared $3 \beta 2 \mathrm{~S}$ with two mutant oligonucleotides. Oligo M1 changed the last two Gs of the $\mathrm{G}_{4}$ stretch to As, while oligo M2 changed the first two Gs in the same way (Fig. 3B). When used in EMSAs, M1 was unable to bind Sp3, while the $3 \beta 1-\mathrm{A}$ band was unaffected (Fig. 3A, left, lane 2). M2 bound Sp3 similarly to as is seen with wild type $3 \beta 2 \mathrm{~S}$, while the $3 \beta 1-\mathrm{A}$ band was severely diminished (Fig. 3A, left, lane 3). This result indicates that the distal two Gs in the sequence 5'-TGGGGT-3' are essential for Sp3 binding, and not necessary for $3 \beta 1-\mathrm{A}$ binding. The proximal two Gs are not required for Sp3 binding, but are important for $3 \beta 1-\mathrm{A}$ factor binding.

Next we asked what is the contribution of the long stretch of As to 3 $\beta 1$-A factor binding, which accounts for as many as eight and six residues in the HSD3B1 and HSD3B2 gene respectively. We disrupted the $\mathrm{A}_{6}$ sequence by changing the five $\mathrm{As}$ immediately preceding the TG box to CGTTG (oligo $3 \beta 2 \mathrm{mS}$, Fig. 3B) and found that the substitution completely prevents formation of the 3ß1-A band (Fig. 3A, lane 4) while unable to form any additional complex. To determine what is the minimal number of As required for restoring the $3 \beta 1-A$ binding activity, we created a series of three oligos that reinstate two, three and four As respectively $\left(A_{2}, A_{3}\right.$, and $A_{4}$, Fig. $\left.3 B\right) . A_{2}$ and $A_{3}$ that restore two and three of the $A$ s in front of the TG box, were unable to support $3 \beta 1-\mathrm{A}$ protein binding (Fig. 3A, lanes 5 and 6), while addition of four As resulted in a fully restored $3 \beta 1-\mathrm{A}$ complex (Fig. 3A, lane 7). We also tested a mutant oligo bearing a deletion of the TGGGG sequence, $\Delta \mathrm{T}(\mathrm{G})_{4}$. This deletion, which was expected to prevent binding of the 3 $\beta 1-\mathrm{A}$ and Sp3 proteins, surprisingly abrogated formation of every band seen with the wild type probe except for the $3 \beta 1-A$ band (Fig. 3A, lane 8). In addition to the $3 \beta 1-\mathrm{A}$ band, $\mathrm{M}_{2}$ and all oligos bearing mutations in the A stretch also affected formation of a faster band that appeared to be as specific as the $3 \beta 1-\mathrm{A}$ band (Fig. 3A, appearing in lanes 1, 2 and 8), but whose intensity and/or formation was not consistent in all our EMSA experiments, as later discussed. Lack of competition with the $3 \beta 1-\mathrm{A}$ protein is likely the reason for the stronger $\mathrm{Sp} 3$ binding observed with $\mathrm{B} 2 \mathrm{mS}, \mathrm{A}_{2}$ and $\mathrm{A}_{3}$, as well as with the unknown protein that forms band 3 , the complex of intermediate mobility between the slower and faster Sp3 band, whose binding to the probe is dependent on the integrity of the $\mathrm{A}_{6}$ stretch (Fig. 3A, lanes 5-8 all lack this complex). However, this explanation does not apply to oligo $\mathrm{A}_{4}$, which is expected to show less Sp3 binding as a consequence of its ability in restoring the 3 $31-\mathrm{A}$ band. Interestingly, this oligo, despite binding the 3 $\beta 1-\mathrm{A}$ factor, did not form the faster band discussed above, which is seen with all other samples forming the 3 $\beta 1$-A complex (Fig. 3A lanes 1,2 and 9). It is possible that, in addition to preventing the formation of band 3 , the changes in the $\mathrm{A}$ stretch carried by $\mathrm{A}_{4}$ also affect the ability to form the faster complex, which apparently results in an increased Sp3 affinity for the TG box. However, conformational changes as a consequence of the alteration in the $\mathrm{A}_{6}$ stretch carried by $\mathrm{B} 2 \mathrm{mS}$, $\mathrm{A}_{2}, \mathrm{~A}_{3}$ and $\mathrm{A}_{4}$, may also explain the stronger affinity for Spl family members of these mutated oligo, independently from their ability to bind or not the $3 \beta 1-$ A protein or the faster band.

The results of the mutational analysis presented herein confirmed the hypothesis that the $3 \beta 1-\mathrm{A}$ protein only recognizes a short segment of the 24 bp element. Indeed it was evident that the conserved sequence AAAATGG represents the core-binding region for the $3 \beta 1-\mathrm{A}$ factor, and that the Sp3 core-binding region is the sequence GGTGG. Therefore, the $3 \beta 1-\mathrm{A}$ element and the TG box of the HSD3B2 and HSD3B1 gene appear to be flanking rather than overlapping cis-elements. 


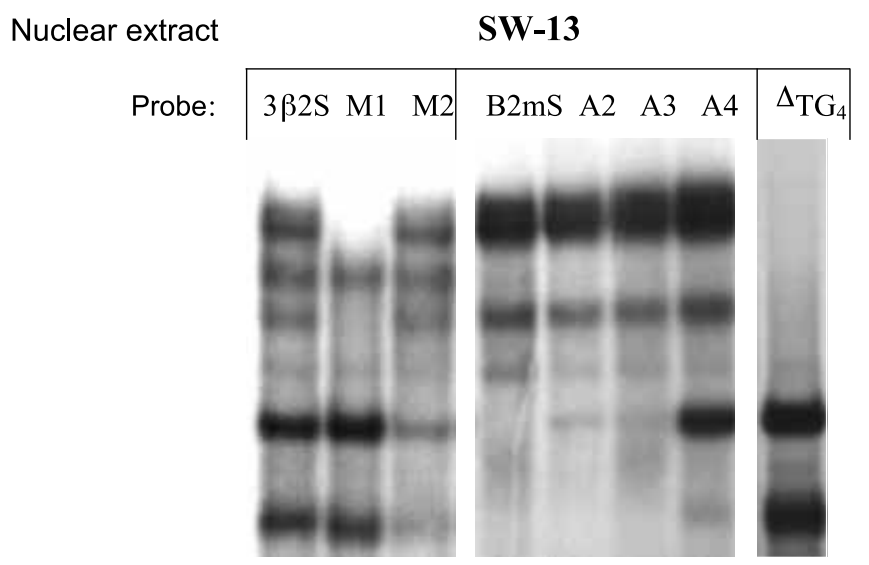

B

\begin{tabular}{|c|c|c|c|}
\hline & & $3 \beta 1-A$ & $\mathrm{Sp} 3$ \\
\hline $3 \beta 2 \mathrm{~S}$ & TTTTTGTAAAAAATGGGGTGGAGGAAAATAAGGCAT & + & + \\
\hline $3 \beta 2 \mathrm{mS}$ & TTTTTGTAccttcTGGGGTGGAGGAAAATAAGGCAT & - & + \\
\hline$A_{2}$ & TTTTTGTAcctAATGGGGTGGAGGAAAATAAGGCAT & - & + \\
\hline$A_{3}$ & TTTTTGTActAAATGGGGTGGAGGAAAATAAGGCAT & - & + \\
\hline$A_{4}$ & TTTTTGTACAAAATGGGGTGGAGGAAAATAAGGCAT & + & + \\
\hline M1 & TTTTTGTAAAAAATGGaaTGGAGGAAAATAAGGCAT & + & - \\
\hline M2 & TTTTTGTAAAAAATaaGGTGGAGGAAAATAAGGCAT & $-1+$ & + \\
\hline$\Delta_{\mathrm{TG}_{4}}$ & GGAATTTTTGTAAAAAA-----TGGAGGAAAATAAGGCATCTGC & + & 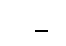 \\
\hline
\end{tabular}

Figure 3 Dissection of the 3 $\beta 1$-A element and TG box in the HSD3B2 gene intron 1. EMSA results obtained with $5 \mu \mathrm{g}$ nuclear extract from SW-13 cells and each of the labeled oligonucleotides whose sequence is shown in (B). (A) Left: comparison of the binding ability of mutants M1 and M2 with the shifted band pattern formed by oligo 3ß2S. Middle: the effect of mutations altering the stretch of $A s$ in the type II 3 $\beta 1-A$ element is shown. Right: the complexes formed by oligo $\Delta \mathrm{T}(\mathrm{G})_{4}$ are shown. (B) Nucleotide sequence of the $3 \beta 2 S$ oligonucleotide and its mutants used in this study. Small letters indicate the mutated nucleotides. The name of each oligo is shown on the left side of each sequence. The enlarged sequence at the bottom of the oligo list summarizes the analysis results, with the minimal nucleotides required for $3 \beta 1-A$ factor binding showed in bold capital letters, and the minimal nucleotides required for Sp3 binding showed in cursive capital letters. Dotted lines substitute for the flanking nucleotides not involved in direct binding. The ability of each oligo to bind YY1 and/or Sp3 is summarized in the panel at the right side of the sequence alignment. +, binding; -, no binding; $-/+$, partial binding.

The discovery that the $3 \beta 1-\mathrm{A}$ protein only requires two of the four Gs to bind the 3 $\beta 1-\mathrm{A}$ element, explains the apparently aberrant behavior of oligo $\Delta \mathrm{T}(\mathrm{G})_{4}$ that formed the $3 \beta 1-\mathrm{A}$ band despite bearing a deletion encompassing the $\mathrm{G}_{4}$ stretch. Analysis of this oligonucleotide sequence reveals that the two $\mathrm{G}$ residues critical for $3 \beta 1-\mathrm{A}$ protein binding are provided by the sequence immediately following the deletion, thus restoring the AAAATGG sequence (Fig. 3B). Instead, Sp3 binding is no longer supported by this oligo, indicating that the sequence GGAGG is unable to functionally replace the sequence GGTGG. The effect of each mutation on the ability to sustain $3 \beta 1-\mathrm{A}$ and/or Sp3 protein binding is summarized in Fig. $3 \mathrm{~B}$ in the right panel next to each oligo sequence. 
A

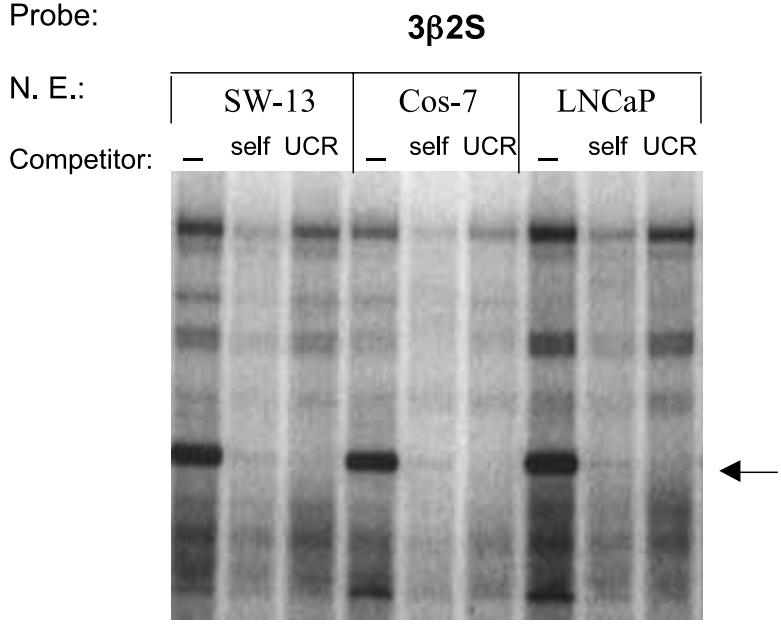

B

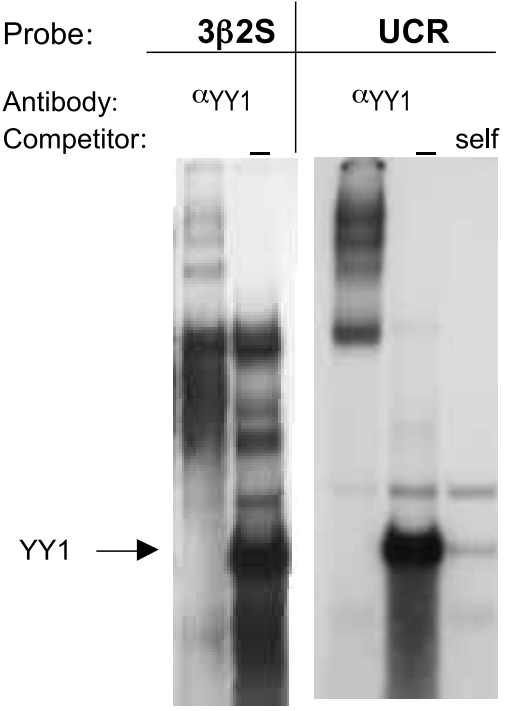

C

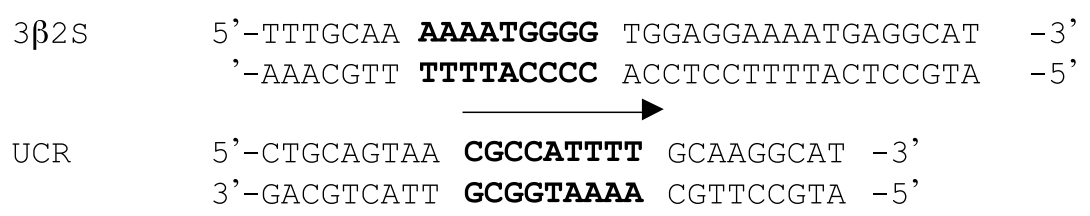

Figure 4 The $3 \beta 1$-A protein is antigenically related to transcription factor YY1. (A) EMSA result obtained when $3 \mu \mathrm{g}$ nuclear extracts from the indicated cell lines were incubated with the $3 \beta 2 S$ probe without $(-)$ and with the indicated competitor oligomers. (B) Three micrograms of nuclear extracts from SW-13 cells were pre-incubated as specified in Materials and methods with and without $1 \mu \mathrm{l}$ anti-YY1 polyclonal antibody with the indicated probes. UCR self-competition is shown in lane 5 to confirm band specificity. Arrows between the two gel shift panels point to the 331-A band here shown as YY1. (C) The name and sequences of the oligomers encompassing the 3 $\beta 1-A$ element and UCR consensus utilized in the experiment are shown. The region known to bind YY1 in the UCR oligo and the homologous region in the $3 \beta 2 S$ oligo is shown in bold letters. The arrow indicates orientation of the YY1 binding region as previously proposed.

\section{YY1 is the protein forming the 3ß1-A complex}

The sequence AAAATGG, that represents the core-binding region of the $3 \beta 1-\mathrm{A}$ factor, is almost identical to the UCR (upstream conserved region) of the Moloney murine leukemia virus, which is known to bind the transcription factor UCRBP (Flanagan et al. 1992), later identified as the murine YY1 (Safrany \& Perry 1993). The UCR, which is only one of many consensus sites known to bind YY1 (Shi et al. 1997), all sharing the CGAT core motif, was later found also in many other viral and cellular genes. The 3 $31-\mathrm{A}$ factor core-binding region matches the UCR nucleotide sequence seven out of nine nucleotides (Fig. 4G). To find out if the $3 \beta 1-\mathrm{A}$ band is formed by $\mathrm{YY} 1$, an oligonucleotide containing the UCR element was tested in EMSA experiments in competition with 

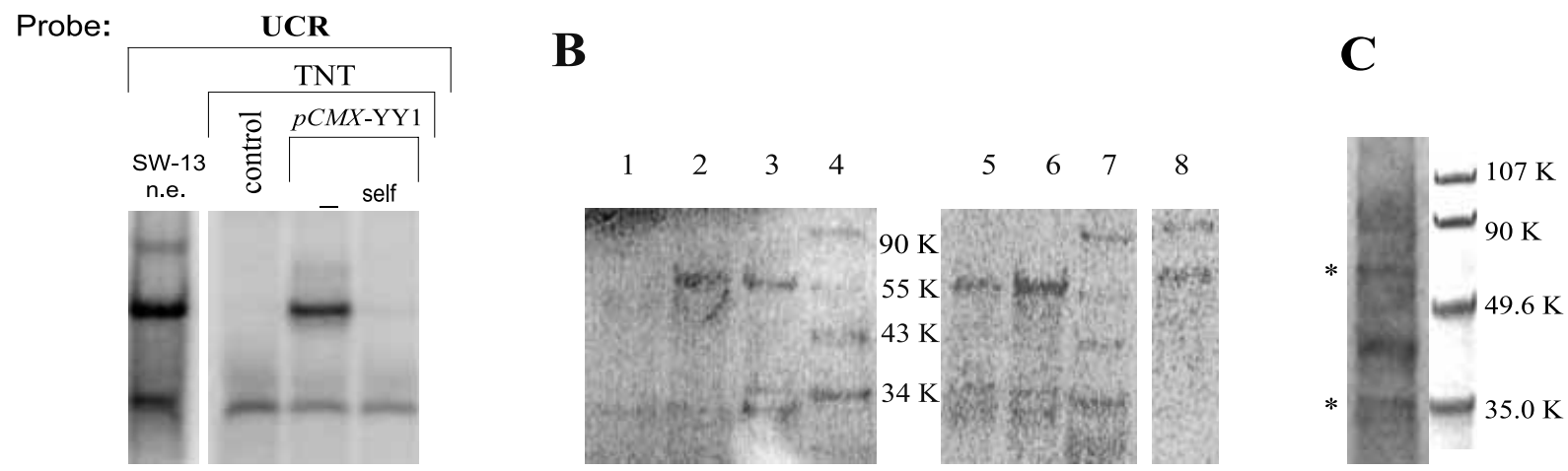

Figure 5 The 3 $31-A$ band corresponds to full-length $Y Y 1$. (A) Gel shift assay comparing the electrophoretic mobility of complexes formed by ${ }^{32} \mathrm{P}$-labeled UCR oligomer incubated with $3 \mu \mathrm{g}$ of SW-13 cell nuclear extract (lane 1), with $5 \mu \mathrm{l}$ of a no-template in vitro TNT reaction (lane 2), and the same volume of in vitro obtained YY1 protein without (lane 3) or with (lane 4) self-competition. A fraction of the autoradiogram is shown. (B) The molecular mass of in vitro synthesized YY1 was compared with YY1 protein from cell nuclear extracts by Western blot analysis. Lane 1, $10 \mu \mathrm{l}$ TNT control reaction in presence of empty $p C M X$-L1 vector; lane 2, $10 \mu \mathrm{I}$ TNT reaction on $p C M X$-YY1; lane 3, $20 \mu \mathrm{g} \mathrm{SW}-13$ nuclear extract; lanes 4 and 7, molecular mass standards; lane 5, $20 \mu \mathrm{l}$ crude isolate of A-3ß2-bound proteins from SW-13 cell nuclear extract; lanes 6 and $8,20 \mu \mathrm{g}$ of nuclear extract from LNCaP cells. Lanes 1-7, samples treated with rabbit polyclonal anti-YY1 antibody directed against the full-length protein. Lane 8, sample treated with rabbit polyclonal anti-Sp3 antibody directed against the carboxy-terminus. (C) Coomassie staining of a $12 \%$ SDS acrylamide gel. Left, $20 \mu \mathrm{l} \mathrm{A-3 \beta 2-bound} \mathrm{proteins} \mathrm{isolated} \mathrm{from} 300 \mu \mathrm{g}$ nuclear extracts from SW-13 cells; right, the low range Biorad pre-stained SDS-PAGE standards are shown. Asterisks mark the position of the two bands recognized by anti-YY1 antibody in the Western blot experiments.

the $3 \beta 2 \mathrm{~S}$ probe. As expected, a 100-fold molar excess of unlabeled $3 \beta 2 \mathrm{~S}$ oligo competed any band formed by the probe with nuclear extract from three different cell lines (Fig. 4A, lanes 1 and 2, 4 and 5 and 7 and 8). Addition of 100-fold molar excess of cold UCR oligo resulted in the disappearance of the $3 \beta 1$-A band (Fig. 4A, lanes 3, 6 and 9), suggesting that the factor binding to the $3 \beta 2 \mathrm{~S}$ probe - and therefore $3 \beta 1 \mathrm{~S}$ as well as $3 \beta 1$ and $3 \beta 2-$ is able to recognize the UCR element. The competition was specific, as the Sp3 band was unaffected. Furthermore, after incubation with SW-13 cell nuclear extract ${ }^{32}$ P-labeled UCR was shifted into a major complex with the same electrophoretic mobility as the $3 \beta 1-\mathrm{A}$ band formed by $3 \beta 2 \mathrm{~S}$ probe (Fig. $4 \mathrm{~B}$, compare lane 2 with lane 4). The complex was specific, as competed out by a 100-fold molar excess of unlabeled UCR (Fig. 4B, lane 5). Addition of a rabbit polyclonal antibody directed against full-length YY1 into the binding reactions resulted in the disappearance of both the $3 \beta 1-\mathrm{A}$ band formed by $3 \beta 2 \mathrm{~S}$ probe and the specific complex formed by UCR probe, and a complicated pattern of supershifted bands was seen with both probes (Fig. 4B, lanes 1 and 3). These results suggest that the protein forming the $3 \beta 1-\mathrm{A}$ band is the transcription factor YY1 or a factor antigenically related to YY1. As YY1 is known as a $68 \mathrm{kDa}$ protein, while the size of the $3 \beta 1-\mathrm{A}$ factor was estimated to be $37 \mathrm{kDa}$ by Guerin et al. (1995), we compared the size of the band shifted by labeled UCR oligomer from SW-13 cell nuclear extract with in vitro-translated YY1. The in vitro obtained protein from plasmid $p C M X-Y Y 1$ in gel retardation assays did shift the UCR probe forming a complex of the same mobility as the one observed with nuclear extracts (Fig. 5A, compare lanes 1 and 3). Such a band was specific to UCR (Fig. 5A, lane 4), and it was not formed when the probe was reacted with an in vitro transcription/translation reaction performed in absence of template (Fig. 5A, lane 2), which indicates that the band is not formed by interaction of UCR with a protein from the rabbit reticulocyte lysate. Western blotting analysis revealed that anti-YY1 antibody - the same antibody used in our EMSAs - recognized a band of molecular mass slightly above $55 \mathrm{kDa}$ for the in vitro transcribed/translated YY1 protein (Fig. 5B, 
lane 2) and nuclear extracts from both SW-13 (Fig. 5B, lane 3) and LNCaP cells (Fig. 5B, lane 6) as well. This band was not formed in negative control reactions consisting of an in vitro transcription/translation coupled reaction without template (Fig. 5B, lane 1). This result indicated that the $3 \beta 1-\mathrm{A}$ band formed by nuclear extracts with UCR, as well as $3 \beta 2$ and $3 \beta 2 \mathrm{~S}$ oligomers, corresponds to full-length YY1 protein. In addition to the full-length band, anti-YY1 antibody recognized also two additional bands of lower molecular mass. A band approximately of $35 \mathrm{kDa}$ and another band around $30 \mathrm{kDa}$ could be seen with both nuclear extract and TNT rabbit reticulocyte lysate. To confirm that YY1 binds the $3 \beta 2$ probe and that it can eventually be co-purified from the bound proteins as differently sized polypeptides, we have used a modification of the Acrydite technology method for the isolation of DNA binding proteins recently proposed by Nelson et al. (2002). Briefly, proteins from SW-13 or LNCaP cell nuclear extracts were incubated in binding buffer with a $3 \beta 2$ oligomer whose upper strand carried an Acrydite moiety at its $5^{\prime}$ prime. Then the oligomer was immobilized to acrylamide as previously described (Nelson et al. 2002) and the unbound proteins were separated from the bound complexes by electrophoresis. An aliquot of a crude preparation, consisting of eluted and concentrated 3 $\beta 2$-binding proteins from recovered acrylamide slices, reacted with anti-YY1 antibody in Western blots, forming three bands of the same molecular mass as obtained with unbound nuclear extract proteins (Fig. 5B, lane 5). Likely because of contaminants in these samples and our loss-prone modification of the original method, the antibodyrecognized bands were less intense than expected, particularly when compared with the bands from unbound nuclear proteins. Coomassie staining of an SDS gel of the same preparation revealed bands whose size were identical to the YY1 specific bands (Fig. 5C). In addition, an intense band of molecular mass intermediate to 35 and $49 \mathrm{kDa}$ was also observed, that was not recognized by anti-YY1 antibody. Sp3 antibody, also a rabbit polyclonal antiserum, recognized the proper Sp3 specific bands of 105 and $73 \mathrm{kDa}$, but failed to recognize the 30 and $35 \mathrm{kDa}$ bands (Fig. 5B, lane 8). These results indicate that at least three different YY1 polypeptides were specifically recognized by antiYY1 antibody, corresponding to the full-length protein, and to two fragments of about 35 and $30 \mathrm{kDa}$. They also indicate that these YY1 polypeptides bind the $3 \beta 2$ oligomer, which is consistent with the previously estimated size of the $3 \beta 1-\mathrm{A}$ factor and is likely due to proteolytic degradation of YY1.

\section{Existence of a second YY1 site within the HSD3B2 and HSD3B1 gene intron 1}

Established that the sequence AAAATGG within the $3 \beta 1-\mathrm{A}$ element binds YY1, as well as that YY1 and the 3 $\beta 1-\mathrm{A}$ factor are identical, we observed that a similar sequence is located in reverse orientation about 35 nucleotides downstream from the TG box in type II intron 1. Because of a substitution $T / G$, the site is not perfectly conserved in the type $\mathrm{I}$ intron 1 at the same location. However, another substitution $\mathrm{A} / \mathrm{G}$ at nucleotide +138 creates a variant of the sequence immediately following the TG box in the type $\mathrm{I}$ intron (AAAATGAGG in type I, AAAATAAGG in type II). To verify whether or not these sequences are able to bind YY1, we designed the oligos shown in Fig. $6 \mathrm{~B}$ and tested them in EMSAs. As shown in Fig. 6A, the EMSA experiments confirmed the ability of YY1 to bind the HSD3B2 gene intron 1 $35 \mathrm{bp}$ downstream from the $3 \beta 1-\mathrm{A}$ element (lane 5). YY1 recognized oligo 147 with an affinity slightly lower than the efficiency exhibited by binding to the UCR and even to the $3 \beta 1-A$ element. This discovery is in agreement with our findings that only the two proximal $\mathrm{G}$ residues are absolutely required for YY1 binding within the 3 $\beta 1$-A element (Fig. 3). Further in accord with the results of the mutational analysis shown in Fig. 3, the corresponding sequence in type $\mathrm{I}$ intron 1 was not able to bind YY1 (Fig. 6A, lane 6) because of its bearing only three out of the four required As. Oligo 126, matching the putative YY1 binding site created by the A+138/G substitution was able to bind YY1 (Fig. 6A, lane 8), but with much lower affinity as only one of the two required $\mathrm{Gs}_{\mathrm{s}}$ is present. Oligo 125, matching the corresponding region in the type II intron was unable to bind YY1 as it lacks the two required proximal Gs (Fig. 6A, lane 7). In Fig. 6B, along with the double stranded sequence of the oligomers used in this study, the ability of each oligo in binding YY1 is exemplified next to each sequence by a positive (binding) or negative (no binding) sign. 
A

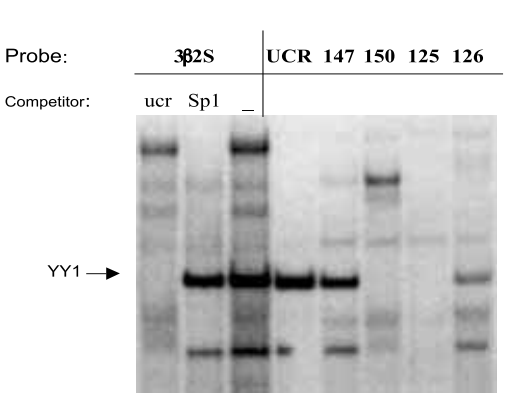

B

$3 \beta 1-\mathrm{A} / \mathrm{Y} 1$

UCR

$147 / 175$ (II)

$150 / 178(I)$

$125 / 150($ II )

$126 / 151(I)$

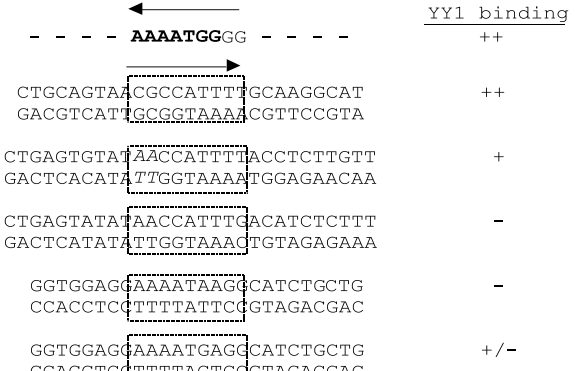

CCACCTCETTTTACTCOGTAGACGAC

C

HSD3B1
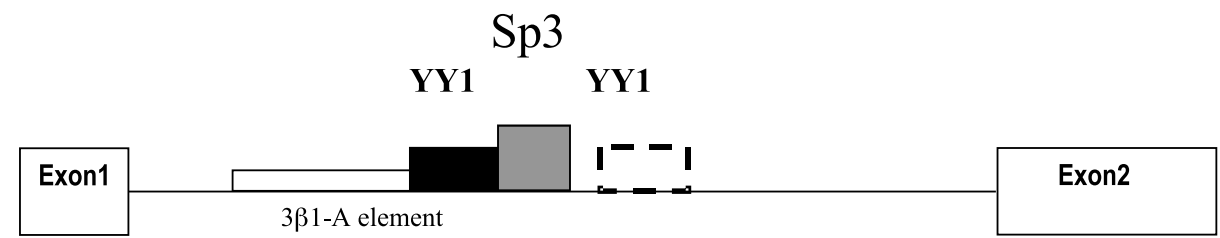

Sp3

YY1

HSD3B2

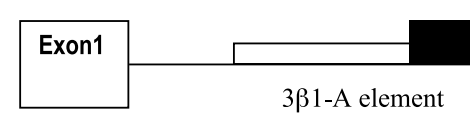

3ß1-A element

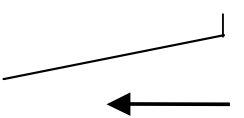

$+111$

TGCAAAAAAAATGGGGTGA

$+111$

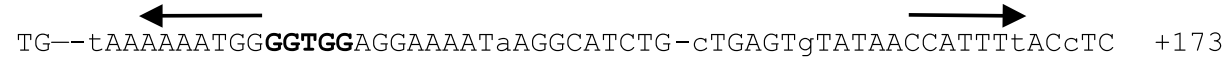

Figure 6 Existence of a second YY1 binding site within the HSD3B1 and HSD3B2 gene Intron 1.

(A) EMSA experiment carried out with $5 \mu \mathrm{g} \mathrm{SW}-13$ nuclear extracts incubated with each of the oligomers indicated as probe. Competition with 100-fold molar excess of UCR and Sp1 oligomers is also shown for the $3 \beta 2 S$ probe. -, no competition. An arrow points at the YY1 band, previously known as $3 \beta 1-A$ band. Only the slower migrating $3 \beta 2 S$ probe is shown. (B) The double stranded sequence of the oligomers used in the study is shown. The name of the mutant oligomers specifies the first and last nucleotide of the intron 1 sequence they encompass. (I), (II) identifies oligos matching to type I or type II introns respectively. The nucleotides involved in the YY1 binding core within the 3 $\beta 1$-A element is shown as a reference, with dotted lines replacing the $5^{\prime}$ and $3^{\prime}$ flanking nucleotides. The black arrow indicates orientation of the YY1 binding site. Dotted lines encase the putative YY1-like binding region in each oligomer for sequence comparison. The ability of each oligomer to bind YY1 is summarized. ++, strong binding; +, binding; +/-, weak binding; -, no binding. (C) Upper: a cartoon illustrates the different organization of the two YY1 binding sites in respect of the TG box in the HSD3B1 and HSD3B2 gene intron 1. Solid and dashed boxes represent stronger and weaker YY1 binding respectively. Open or filled square boxes represent weaker and stronger Sp3 binding to the TG box respectively. A narrow rectangular box represents the 24 nucleotides previously identified as the 3 $\beta 1$-A element in the HSD3B1 gene intron 1. A similar schematization is used to represent the not perfectly conserved region in the HSD3B2 gene. Lower: the sequence alignment of the type I and type II intron 1 from nucleotide +111 to +174 (type I) or to +173 (type II) shows the nucleotide changes involved in the formation of the second and not conserved YY1 binding site. Small letters identify the nucleotide substitutions, dotted lines replace missing nucleotides. Bold letters outline the nucleotide essential for Sp3 binding. Arrowheads identify the nucleotides involved in YY1 binding and the orientation of such binding. Bold solid arrowheads indicate strong binding, a bold open line arrowhead indicates weaker YY1 binding. 


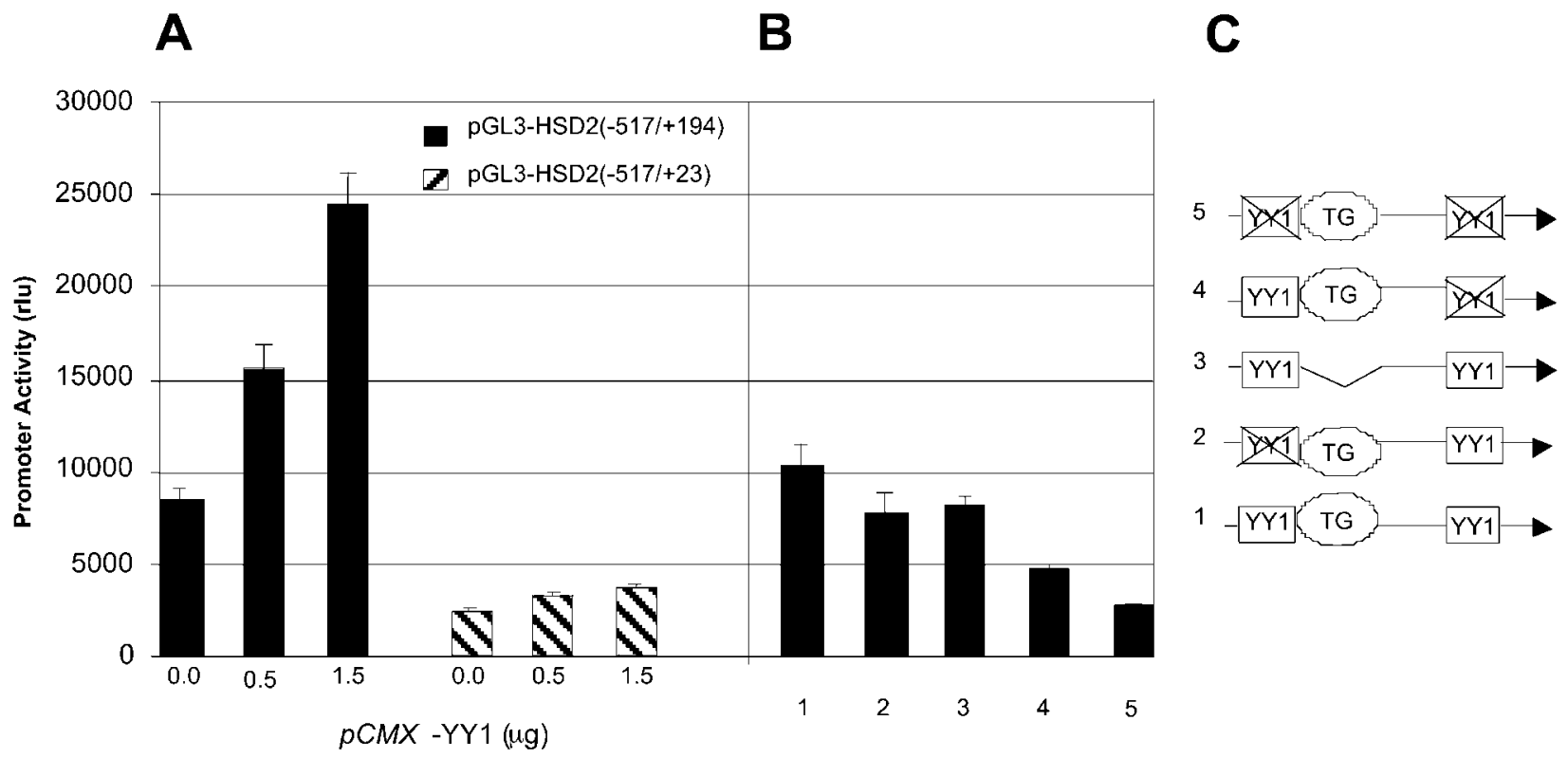

Figure 7 Functional analysis of YY1 in the HSD3B2 gene intron 1-mediated enhancement of basal promoter activity. (A) YY1 is responsible for the boost in promoter activity mediated by the HSD3B2 gene intron 1. SW-13 cells were plated at $3.2 \times 10^{5}$ cells/well in 12-well plates and transfected as detailed in Materials and methods with plasmids $p G L 3-H S D 2(-517 /+193)$ and $p G L 3-H S D 2(-517 /+23)$ in the presence of the indicated amounts of $p C M X-Y Y 1$ expression vector. The promoter activity is shown, expressed as luciferase light units (lu), and data are expressed as the mean of two separate experiments each performed with duplicate samples. The standard deviations are shown. (B) Functional analysis of YY1 binding sites and TG box in the context of the HSD3B2 gene intron 1. The activity of luciferase reporter plasmid $p$ GL3-HSD2 $(-246 /+193)$ is compared with the activity of mutants designed to alter YY1 and Sp3 binding within intron 1 in the absence of YY1 expression plasmid. The luciferase activity is reported as luciferase units (lu) mean of three separate experiments each performed in duplicates. A schematization of the nucleotide deletion and substitutions created by site-directed mutagenesis in pGL3-HSD2 $(-246 /+193)$ is shown next to each activity bar. 1, pGL3-HSD2 $(-246 /+193)$ parental vector; 2, the B2mS substitution changes five As to CCTTC eliminating $Y Y 1$ binding site to the 3 31 -A element; 3, deletion $\Delta T(G)_{4}$ eliminates Sp3 binding to the TG box without affecting YY1 binding to the 3 31 -A element; 4 , substitution of the four As to CCTT prevents YY1 binding to the distal binding site; 5 , a double mutation abrogates YY1 binding to intron 1.

This analysis revealed that YY1 recognizes the same sequence in two different regions within intron 1 of both the HSD3B1 and HSD3B2 genes. One site is conserved between the two genes for nucleotide sequence and location, it being the seven conserved nucleotides of the $3 \beta 1-\mathrm{A}$ element immediately juxtaposed to the $5^{\prime}$ prime of the TG box; the second site differs between the two genes for location and orientation. In type I intron 1 the second YY1 site is a slight variant of the AAAA TGG sequence located eight nucleotides downstream from the $3 \beta 1-\mathrm{A}$ element, immediately following the $3^{\prime}$ prime of the TG box. In type II intron 1 the second site lays in reverse orientation $35 \mathrm{bp}$ apart from the $3 \beta 1-\mathrm{A}$ element. A schematic representation of these findings is presented in Fig. 6C.

\section{YY1 enhances the HSD3B2 gene basal promoter activity by binding to the two identified binding regions within the gene intron 1}

To explore whether or not YY1 is functionally involved in the boost of basal promoter activity mediated by the HSD3B2 gene intron 1, we overexpressed YY1 in the presence of the same reporter constructs (shown Fig. 1B) we earlier used to assess the functional relevance of the intron in transient transfection assays. As shown in Fig. 7A, co-transfection with increasing amounts of YY1 expression plasmid stimulated the fulllength construct $p G L 3-\mathrm{HSD} 2(-517 /+193)$ in a dose-dependent manner up to 3-fold, while it failed to stimulate the intron-less construct 
$p G L 3-H S D 2(-517 /+23)$. This result showed that YY1 stimulates the luciferase expression driven by the HSD3B2 gene sequence by binding within intron 1. To confirm YY1 as the factor responsible for the enhanced basal transcription observed in the presence of intron 1 we investigated the contribution of each of the two YY1 binding sites by comparing the activity of a luciferase reporter construct encompassing the HSD3B2 gene sequence from nucleotide -246 to nucleotide + 193, pGL3-HSD2 $-246 /+193)$, with reporter constructs in which the same region was abrogated of YY1 binding to either the 3 $\beta 1-A$ element or the distal site or both. For this purpose, the four As required for YY1 binding were changed by site-directed mutagenesis using oligo B2mS (Fig. 3) to abolish YY1 binding in front of the TG box; an oligo identical to oligo 147 (shown in Fig. 6), except for having the four critical As changed to CCTT, was used to eliminate YY1 binding to the distal site. We also tested a construct bearing the $\Delta T(G)_{4}$ deletion that eliminates the sequence TGGGG (Fig. 3), thus preventing Sp3 binding but not YY1 binding. Fig. 7B presents the results of transient transfections in SW-13 cells obtained with pGL3$\operatorname{HSD} 2(-246 /+193)$ and its mutant variants, which did not involve co-transfection of YY1 expression vector. Preliminary experiments revealed that the basal activity of $p G L 3-$ HSD2 $(-246 /+193)$ was comparable with the basal activity of $p G L 3-H S D 2(-517 /+193)$, indicating that the HSD3B2 gene sequence from -517 to -246 does not significantly affect the basal promoter activity. Surprisingly, inability of YY1 to bind its site within the 3 $\beta 1-A$ element had little effect on the basal promoter activity (Fig. 7B, activity bar 2). A similar effect was seen with the construct that bears a deletion of the TG box (Fig. 7B, activity bar 3). Therefore, neither YY1 nor Sp3 binding to the juxtaposed 3 $\beta 1$-A element and TG box plays any major role in the intron 1-mediated increase of the HSD3B2 gene basal promoter activity. Instead, preventing binding of YY1 to the distal site resulted in a $50 \%$ decrease of basal transcription (Fig. 7B, activity bar 4). Complete abrogation of YY1 binding within intron 1 resulted in a basal promoter activity that was only $30 \%$ of the wild type activity (Fig. 7B, activity bar 5). Remarkably, this last result reproduced the loss of activity seen with the promoter construct missing the whole intronic sequence and also it made evident that Sp3, or any other Spl family members, has no ability to direct the boost in basal activity through intron 1 of the HSD3B2 gene. Thus, the proximal YY1 site within the $3 \beta 1-\mathrm{A}$ element and the distal YY1 binding site contribute to boost the HSD3B2 gene basal transcription. Similar results were obtained with $\mathrm{COS}-7$ and LNCaP cells (data not shown).

\section{Discussion}

Despite the pivotal role of the $3 \beta$-HSD type II enzyme in the biosynthesis of all steroids, the molecular mechanisms that regulate the gene expression are yet to be fully understood. Lately, important studies have been published concerning the significance of SF-1 in the HSD3B2 gene expression and its synergistic effect with phorbol ester (Leers-Sucheta et al. 1997), as well as its regulation by cytokines (Cote et al. 2000, Gingras et al. 2001), gonadotropins (Feltus et al. 1999) and glucocorticoids (Feltus et al. 2002). However, no study has investigated the role of intron 1 in the HSD3B2 gene basal activity so far, despite a previous finding that the highly homologous HSD3B1 gene requires the activating $3 \beta 1-\mathrm{A}$ element within the first intron to keep the basal promoter activity to its full potential by binding the unknown 3 $\beta 1-\mathrm{A}$ factor. In this study we have shown that the HSD3B2 gene intron 1 is required to achieve maximal basal activity levels of the promoter region. Despite the suggestion that the HSD3B1 and HSD3B2 genes may not share the 3 $\beta 1$-A element (Guerin et al. 1995), we have proved the existence of such a cis-acting element in the intron 1 of the HSD3B2 gene. More specifically, we have proved that the $3 \beta 1$-A protein binds to a conserved region of seven nucleotides of the 3 $\beta 1-\mathrm{A}$ element in both genes, through a mutational analysis that has ultimately helped us pinpoint similarities between the $3 \beta 1-\mathrm{A}$ binding core and the UCR core recognized by the multi-role transcription factor YY1. We have shown evidence that $\mathrm{YY} 1$ is indeed the protein binding in vitro to the $3 \beta 1-\mathrm{A}$ element by competition analysis and use of anti-YY1 antibody.

YY1 complies with many of the characteristics attributed to the 3ß1-A factor, as it is ubiquitously and constitutively expressed (Austen et al. 1997, Shi et al. 1997). It contains four zinc-finger domains 
with homology to the GLI-Kruppel family of proteins (Shi et al. 1991), thus explaining the $3 \beta 1-\mathrm{A}$ protein requirement for zinc ions. However, despite a predicted molecular mass of $44 \mathrm{kDa}, \mathrm{YY} 1$ is known to migrate as a $65-68 \mathrm{kDa}$ protein in SDS gels (Shi et al. 1997), whereas the 3 $\beta 1-\mathrm{A}$ factor was attributed a molecular mass of $37 \mathrm{kDa}$ by UV-crosslinking analysis (Guerin et al. 1995). This apparent discrepancy can be explained by recent findings that claim YY1 proteolytic mechanisms as part of degradation processes and even tissuespecific signal transduction pathways. Specifically, YY1 was shown to be the target of calpein II in a mechanism aimed at downregulating YY1 protein during muscle development (Walowitz et al. 1998), which generates a $40 \mathrm{kDa}$ polypeptide. Moreover, a nuclear cathepsin B-like protease activity appears to degrade YY1 (Pizzorno 2001) generating two fragments of about 30 and $40 \mathrm{kDa}$, a phenomenon associated with the progression of undifferentiated to differentiated NT2 cells upon treatment with retinoic acid. In this case, the larger cleavage product, representing the carboxy-terminal portion of YY1 containing the zinc-finger domain, was shown to bind the cognate DNA consensus forming a faster complex in gel shift assays. Bovolenta et al. (1999) found that administration of interleukin 2 to individuals affected by HIV-induced downregulation of YY1 protein through activation of an unidentified proteolytic activity, which resulted in appearance of a faster YYl band of unknown molecular mass in gel shift analysis. Interestingly, when YY1 was first isolated for its ability to bind the UCR site, a $40 \mathrm{kDa}$ antigenically related protein was co-purified with it (Becker et al. 1994) and found to account for much of the UGR binding activity in T-lymphocytes along with YY1. In light of the latest findings, the $40 \mathrm{kDa}$ protein could have been a truncated form of YY1. Therefore, it cannot be excluded that in the previous study on the HSD3B1 gene (Guerin et al. 1995) during the procedures required for UVcrosslinking analysis a pre-existing truncated YY1 fragment was also isolated. In addition to the $37 \mathrm{kDa}$ band attributed to the $3 \beta 1-\mathrm{A}$ protein, according to Guerin and coworkers, the UVcrosslinking analysis produced two additional specific complexes that, once approximately corrected for the contribution of the oligonucleotide, did yield molecular mass compatible with fulllength YY1. In support of the above suggestions, we did observe frequently but not constantly appearance of a band of faster mobility with

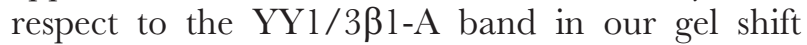
experiments, specific to both $3 \beta 1 \mathrm{~S} / 3 \beta 2 \mathrm{~S}$ and UCR probes (Fig. 3, and seen also in Fig. 6). Formation of this faster band seems to be sensitive to slight experimental changes of $\mathrm{pH}$ or ionic strength that facilitate binding of pre-existing factors/fragments, and also it might be influenced by the nucleotides flanking the consensus, as our deletion construct $\Delta \mathrm{T}(\mathrm{G})_{4}$ was able to form this faster complex at all times. In addition, use of anti-YY1 antibody in gel shift experiment showed more than one supershifted band. We exclude that YY1 fragmentation occurred during the manipulation of the nuclear extracts and incubation of the binding reactions. Indeed, despite absence of protease inhibitors in our nuclear extracts, incubation of the extract at $37^{\circ} \mathrm{C}$ for $1 \mathrm{~h}$ before probe addition in EMSA binding reactions did not favor the appearance of faster bands in control experiments that did not show these bands in the untreated samples (not shown). Although we cannot at this time explain their origin, neither their significance in relation to the HSD3B2 gene basal activity, we have demonstrated that two bands of similar molecular mass to the previously identified YY1 fragments could be isolated from nuclear factors bound to the 3ß1-A element. The $35 \mathrm{kDa}$ YY1 fragment could likely account for the $37 \mathrm{kDa}$ band previously attributed to the $3 \beta 1-\mathrm{A}$ factor.

In addition to having characterized YY1 as the factor binding the $3 \beta 1-\mathrm{A}$ element, we have identified a second YY1 binding site in both type I and type II introns. Indeed, a sequence 100\% identical to the region we have found to bind YY1 within the $3 \beta 1-\mathrm{A}$ element was found to bind YY1 at the end of the HSD3B2 intron 1. Interestingly, this sequence is reversed in respect of the orientation of the identical sequence within the 3 $\beta 1-\mathrm{A}$ element. A weaker YY1 binding site was found at the $3^{\prime}$ end of the TG box in the HSD3B1 intron 1. This last finding might explain why Sp3 binds with better efficiency the $3 \beta 1 \mathrm{~S}$ probe than the $3 \beta 2 \mathrm{~S}$ probe. We could bring the band intensity formed by $\mathrm{Sp} 3$ bound to $3 \beta 2 \mathrm{~S}$ to that seen with the $3 \beta 1 \mathrm{~S}$ probe when we changed the only nucleotide that differs between the type I and type II sequence. This one nucleotide mismatch in position +136 , A in type II, $+138 \mathrm{G}$ in type I (Fig. 2G), does not affect the region strictly required for Sp3 binding, 
neither is it part of a region that may represent another Sp1/Sp3 binding site, as demonstrated by the fact that oligos 125 and 126 are unable to shift Spl family members (Fig. 6A). It is possible that a $\mathrm{G}$ instead of $\mathrm{A}$ at the $3^{\prime}$ end of the intron 1 TG box may facilitate Sp3 binding to a region rich in As and $\mathrm{T}_{\mathrm{s}}$, by reducing or disrupting any intrinsic DNA structure. However, a more likely explanation is that in the fewer cases when YY1 is sitting onto the less efficient site outside the 3 $\beta 1-A$ element, Sp3 displaces it more easily than it can displace YY1 bound to the stronger site within the $3 \beta 1-\mathrm{A}$ element, which results in a better competition of Sp3 for the type I TG box. Our findings suggest the effectors playing a role in the HSD3B 1 gene basal activity need to be further investigated, as the conclusions of the previous study were based on the analysis of a mutant that affected not only YY1 binding to the 3 $\beta 1-\mathrm{A}$ element but also Sp3. While the importance of Spl was disregarded in the previous study because of the weaker binding of this factor to the $3 \beta 1-\mathrm{A}$ element flanking TG box, we have herein proved the oligomer used in that study could not support proper Spl family member binding, and that Sp3 is the Spl family member that electively binds the region with intensity comparable with the complex formed by YY1. Nevertheless our results in mammalian cells did not evidence any role for $\mathrm{Sp} 3$ in the maintenance of the HSD3B2 gene basal activity, the different organization of the two YY1 binding sites in respect of the TG box in the HSD3B1 gene intron 1, and the consequent improved Sp3 competition for its site in in vitro experiments, suggest that $\mathrm{Sp} 3$ may have a different outcome in the HSD3B1 gene basal promoter activity. The importance of the weaker YY1 binding site immediately flanking the TG box at the $3^{\prime}$ end also needs to be assessed.

We have functionally characterized the importance of YY1 in the intron 1-mediated enhancement of the HSD3B2 gene basal promoter activity. Dissimilarly from the HSD3B1 gene (Guerin et al. 1995), disruption of the YY1 binding site within the $3 \beta 1-\mathrm{A}$ element did not result in a 3 - to 6-fold reduction of promoter activity, an outcome that further contributes to make evident differences in the mechanism implicated in the function of type I and type II intron 1. However, disrupting YY1 binding to the distal site with opposite orientation resulted in a 50\% decrease in basal promoter activity. When both sites were simultaneously eliminated, the residual promoter activity was only $30 \%$ of the wild type promoter activity, a result functionally identical to the lack of the whole intronic sequence. As the two $35 \mathrm{bp}$ apart YY1 binding regions have opposite orientation, and YY1 is known to induce DNA bending by binding to its cognate sequence (Natesan \& Gilman 1993, Kim \& Shapiro 1996), one could speculate that YY1 binding to the two regions within the HSD3B2 intron 1 would induce formation of a loop which might help binding and/or interaction of other factors involved in the HSD3B2 gene basal transcription. As it is known that TBP and TFIID require bending of the TATA box region for optimal binding (Parvin et al. 1995), it is tempting to hypothesize that YY1 binding to intron 1 would help maintain a DNA conformation that facilitates the RNA polymerase complex formation onto the imperfect TATA box (Lachance et al. 1991) of the HSD3B2 gene. Similarly to our study, Kerr et al. (1997) found that extending the human bone sialoprotein gene promoter to include the first 68 nucleotides of intron 1 resulted in a 3- to 7-fold increase in reporter activity in UMR 106-01 BPS cells. Interestingly, the human bone sialoprotein gene possesses an inverted TATA box, and one YY1 binding site was found within the first $30 \mathrm{bp}$ of intron 1. The explanation we suggest is more likely to describe the mechanism of YY1 action through its binding sites in the HSD3B2 gene intron 1 rather than YY1 acting by changing the DNA structure and/or chromatin organization by its ability to recruit factors with intrinsic histone acetylase activity (Thomas \& Seto 1999). Indeed, in preliminary transfection experiments, $66 \mathrm{nM}$ trichostatin A, a drug known to inhibit histone deacetylase thus boosting gene activity by favoring an open chromatin structure, did increase the basal activity of the wild type and double YY1 deletion constructs to a similar extent (3-fold) in transfection experiments. This suggests that $\mathrm{YY} 1$ is not functioning at the intron 1 level by favoring histone acetylation.

Taken together our results indicate that the HSD3B2 gene intron 1 is required for maintaining the gene basal promoter activity at the highest levels observed in transfection experiments with a reporter system, and that YY1 is the factor that mediates such effect by binding to two different regions within intron 1 . As we have also identified YY1 to be the $3 \beta 1-\mathrm{A}$ protein, the trans-activator 
that was attributed a similar role in the HSD3B1 gene, this study points to a major role of YY1 in affecting the basal levels of $3 \beta$-HSD activity. Additional studies will be required to explore the mechanisms implicated in YYl contribution to the basal activity of both the HSD3B1 and HSD3B2 genes.

An important consideration arising from this study and the previous study on the HSD3B1 gene is that nucleotide sequence variants occurring within the HSD3B1 and HSD3B2 gene intron 1 may result in more or less profound changes in gene basal activity, and consequently they should not be excluded from being characterized merely because of their occurrence within an intronic sequence.

\section{Acknowledgements}

We thank Dr Yang Shi for allowing us to use $p C M V$-YY1. We are most grateful to Dr Baruch Frenkel and Dr Amy Lee for critical review of the manuscript. We wish to acknowledge Claudia Wehie for skillful technical assistance, and members of the J K R's laboratory, Troy Phipps above all, for assistance with the ABI PRISM 3100 DNA Sequencer. This work was supported by Department of Defense grant \# 001280 awarded to J K R

\section{References}

Austen M, Lüscher B \& Lüscher-Firzlaff JM 1997 Characterization of the transcriptional regulator YY1. Fournal of Biological Chemistry 272 1709-1717.

Bartsch W, Klein H, Schiemann U, Bauer HW \& Voigt KD 1990 Enzymes of androgen formation and degradation in the human prostate. Annals of the New York Academy of Sciences $\mathbf{5 9 5}$ 53-66.

Becker KG, Jedlicka P, Templeton NS, Liotta L \& Ozato K 1994 Characterization of hUCRBP (YY1, NF-E1, $\delta$ ): a transcription factor that binds the regulatory regions of many viral and cellular genes. Gene 150 259-266.

Bosland MC 2000 The role of steroid hormones in prostate carcinogenesis. Fournal of the National Cancer Institute. Monographs 2000 39-66.

Bovolenta C, Camorali L, Lorini LA, Vallanti G, Ghezzi S, Tambussi G, Lazzarin A \& Poli G 1999 Expression and activation of a C-terminal truncated isoform of STAT5 (STAT5 $\Delta$ ) following interleukin 2 administration or AZT monotherapy in HIV-infected individuals. Fournal of Immunology 163 6892-6897.

Chang BL, Zheng SL, Hawkins GA, Isaacs SD, Wiley KE, Turner A, Carpten JD, Bleecker ER, Walsh PG, Trent JM et al. 2002 Joint effect of HSD3B1 and HSD3B2 genes is associated with hereditary and sporadic prostate cancer susceptibility. Cancer Research 62 1784-1789.
Cote S, Feltus A, Freeman M, Melner MH \& Simard J 2000 IL-4 stimulation of ovarian $3 \beta$-hydroxysteroid dehydrogenase/ $\Delta^{5}-\Delta^{4}$-isomerase type II gene expression: mechanisms of activation. In Proceedings of the 82nd Annual Meeting of Endocrine Society, Toronto, ON Canada 21-24 June 2000. P 1295

Dent GL \& Latchman DS 1993 Transcription Factors: a Practical Approach, edn 2, p 11. Ed. DS Latchman. Oxford: IRL Press, Oxford University Press.

Eldar-Geva T, Hurwitz A, Vecsei P, Palti Z, Milwidsky A \& Rosler A 1990 Secondary biosynthetic defects in women with late-onset congenital adrenal hyperplasia. New England Fournal of Medicine 323 855-863.

Flanagan JR, Becker KG, Ennist DL, Gleason SL, Driggers PH, Levi BZ, Appella E \& Ozato K 1992 Cloning of a negative transcription factor that binds to the upstream conserved region of Moloney murine leukemia virus. Molecular and Cellular Biology 12 38-44.

Feltus FA, Groner B \& Melner MH 1999 Stat5-mediated regulation of the human type II $3 \beta$-hydroxysteroid dehydrogenase/ $\Delta^{5}-\Delta^{4}$-isomerase gene: activation by prolactin. Molecular Endocrinology 13 1084-1093.

Feltus FA, Cote S, Simard J, Gingras S, Kovacs WJ, Nicholson WE, Clark B \& Melner MH 2002 Glucocorticoids enhance activation of the human type II $3 \beta$-hydroxysteroid dehydrogenase/ $\Delta^{5}-\Delta^{4}$-isomerase gene. Fournal of Steroid Biochemistry and Molecular Biology 82 55-63.

Gann PH, Hennekens CH, Ma J, Longcope C \& Stampfer MJ 1996 Prospective study of sex hormone levels and risk of prostate cancer. Fournal of the National Cancer Institute 88 1118-1126.

Guerin S, Leclerc S, Verreault H, Labrie F \& Luu-The V 1995 Overlapping cis-acting elements located in the first intron of the gene for type I $3 \beta$-hydroxysteroid dehydrogenase modulate its transcriptional activity. Molecular Endocrinology 9 1583-1597.

Gingras S, Cote S \& Simard J 2001 Multiple signal transduction pathways mediate interleukin-4-induced $3 \beta$-hydroxysteroid dehydrogenase $/ \Delta^{5}-\Delta^{4}$-isomerase in normal and tumoral target tissues. Fournal of Steroid Biochemistry and Molecular Biology 76 213-225.

Kennett SB, Ulvadia AJ \& Horowitz JM 1997 Sp3 encodes multiple proteins that differ in their capacity to stimulate or repress transcription. Nucleic Acids Research 25 3110-3117.

Kerr JM, Hiscock DRR, Grzesik W, Robey PG \& Young MF 1997 The human bone sialoprotein gene contains an NF-E1/YY1 cis-acting sequence with putative regulatory activity. Calcified Tissue International $60276-282$.

Kim J \& Shapiro DJ 1996 In simple synthetic promoters YY1-induced DNA bending is important in transcription activation and repression. Nucleic Acids Research 24 4341-4348.

Labrie F, Simard J, Luu-The V, Belanger A \& Pelletier G 1992 Structure, function and tissue-specific gene expression of $3 \beta$-hydroxysteroid dehydrogenase/5-ene-4-ene isomerase enzymes in classical and peripheral intracrine steroidogenic tissues. Fournal of Steroid Biochemistry and Molecular Biology 43 805-826.

Lachance Y, Luu-The V, Labrie G, Simard G, Dumont M, de Launoit Y, Guerin S, Leblanc G \& Labrie F 1990 Characterization of human 3 $\beta$-hydroxysteroid dehydrogenase $/ \Delta^{5}-\Delta^{4}$-isomerase gene and its expression in mammalian cells. Fournal of Biological Chemistry $26520469-20475$

Lachance Y, Luu-The V, Verreault H, Dumont M, Rheaume E, Leblanc G \& Labrie F 1991 Structure of the human type II $3 \beta$-hydroxysteroid dehydrogenase $/ \Delta^{5}-\Delta^{4}$-isomerase $(3 \beta$-HSD gene: adrenal and gonadal specificity. DNA and Cell Biology 10 701-711.

Lala DS, Rice DA \& Parker KL 1992 Steroidogenic factor I, a key regulator of steroidogenic enzyme expression, is the mouse homolog of fushi tarazu-factor I. Molecular Endocrinology 6 $1249-1258$ 
Leers-Sucheta S, Morohashi K-I, Mason JI \& Melner MH 1997 Synergistic activation of the human type II $3 \beta$-hydroxysteroid dehydrogenase $/ \Delta^{5}-\Delta^{4}$-isomerase promoter by the transcription factor steroidogenic factor-1/adrenal 4-binding protein and phorbol ester. Fournal of Biological Chemistry 272 7960-7967.

Leibovitz A, McCombs WM, Johnston D, McGoy CE \& Stinson JC 1973 New human cancer cell culture lines. I. SW-13, small-cell carcinoma of the adrenal cortex. Fournal of the National Cancer Institute $\mathbf{5 1}$ 691-697.

Levine LS 2000 Congenital adrenal hyperplasia. Pediatrics in Review 21 159-170.

Luu-The V, Lachance Y, Labrie C, Leblanc G, Thomas JL, Strickler RC \& Labrie F 1989 Full length cDNA structure and deduced amino acid sequence of human $3 \beta$-hydroxy-5-ene steroid dehydrogenase. Molecular Endocrinology 3 1310-1312.

Marker PC, Donjacour AA, Dahiya R \& Cunha G 2003 Hormonal, cellular, and molecular control of prostatic development. Developmental Biology 253 165-174.

Marui S, Castro M, Latronico AC, Elias LL, Arnhold IJ, Moreira AC \& Mendonca BB 2000 Mutations in the type II $3 \beta$-hydroxysteroid dehydrogenase (HSD3B2) gene can cause premature pubarche in girls. Clinical Endocrinology 52 67-75.

Mendonca BB, Russell AJ, Vasconcelos-Leite M, Arnhold IJP, Bloise W, Wajchenberg BL, Nicolau W, Sutcliffe RG \& Wallace AM 1994 Mutation in 3ß-hydroxysteroid dehydrogenase type II associated with pseudohermaphroditism in males and premature pubarche or cryptic expression in females. Fournal of Molecular Endocrinology 12 119-122.

Morissette J, Rheaume E, Leblanc JF, Luu-The V, Labrie F \& Simard J 1995 Genetic linkage mapping of HSD3B1 and HSD3B2 encoding human types I and II 3ß-hydroxysteroid dehydrogenase $/ \Delta^{5}-\Delta^{4}$-isomerase close to D1S514 and the centromeric D1Z5 locus. Cytogenetics and Cell Genetics 69 $59-62$.

Morohashi K, Honda S, Inomata Y \& Omura T 1992 A common trans-acting factor, Ad4-binding protein, to the promoters of steroidogenic P-450s. Journal of Biological Chemistry $\mathbf{2 6 7}$ 17913-17919.

Morrison N, Nickerson DA, McBride MW, Mueller UV, Boyd E \& Sutcliffe RG 1991 Regional chromosomal assignment of human 3-beta-hydroxy-5-ene steroid dehydrogenase to $1 \mathrm{p} 13 \cdot 1$ by non-isotopic in situ hybridization. Human Genetics 87 223-235.

Natesan S \& Gilman MZ 1993 DNA bending and orientation-dependent function of YY1 in the c-fos promoter. Genes and Development 7 2497-2509.

Nelson C, Hendy S, Reid K \& Cavanagh J 2002 Acrylamide capture of DNA-bound complexes: electrophoretic purification of transcription factors. BioTechniques 32 808-815.

Pang S, Wang W, Rich B, David R, Chang YT, Carbunaru G, Myers SE, Howie AF, Smillie KJ \& Mason JI 2002 A novel nonstop mutation in the stop codon and a novel missense mutation in the type II $3 \beta$-hydroxysteroid dehydrogenase

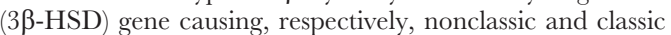
$3 \beta$-HSD deficiency congenital adrenal hyperplasia. Fournal of Clinical Endocrinology and Metabolism 87 2556-2563.
Parvin JD, McCormick RJ, Sharp PA \& Fisher DE 1995 Pre-bending of a promoter sequence enhances affinity for the TATA-binding factor. Nature 23 724-727.

Pizzorno MC 2001 Nuclear cathepsin B-like protease cleaves transcription factor YY1 in differentiated cells. Biochimica et Biophysica Acta 1536 31-42.

Rheaume E, Lachance Y, Zhao HF, Breton N, Dumont M, de Launoit Y, Trudel C, Luu-The V, Simard J \& Labrie F 1991 Structure and expression of a new complementary DNA encoding the almost exclusive 3 $\beta$-hydroxysteroid dehydrogenase/ $\Delta^{5}-\Delta^{4}$-isomerase in human adrenals and gonads. Molecular Endocrinology 5 1147-1157.

Ross RK \& Schottenfeld D 1996 Prostate cancer. In Cancer Epidemiology and Prevention, edn 2, pp 1180-1206. Eds D Schottenfeld \& J Fraumeni. Oxford: IRL Press, Oxford University Press.

Ross RK, Pike MC, Coetzee GA, Reichardt JK, Yu MC, Feigelson H, Stanczyk FZ, Kolonel LN \& Henderson BE 1998 Androgen metabolism and prostate cancer: establishing a model of genetic susceptibility. Cancer Research 58 4497-4504.

Safrany G \& Perry RP 1993 Characterization of the mouse gene that encodes the $\delta / \mathrm{YY} 1 / \mathrm{NF}-\mathrm{E} 1 / \mathrm{UCRBP}$ transcription factor. PNAS 90 5559-5563.

Simard J, Rheaume E, Sanchez R, Laflamme N, de Launoit Y, Luu-The V, van Seters AP, Gordon RD, Bettendorf M \& Heinrich U 1993 Molecular basis of congenital adrenal hyperplasia due to $3 \beta$-hydroxysteroid dehydrogenase deficiency. Molecular Endocrinology 7 716-728.

Simard J, Moisan AM \& Morel Y 2002 Congenital adrenal hyperplasia due to $3 \beta$-hydroxysteroid dehydrogenase/ $\Delta^{5}-\Delta^{4}$-isomerase deficiency. Seminars in Reproductive Medicine 20 $255-276$

Shi Y, Seto E, Chang LS \& Shenk T 1991 Transcriptional repression by YY1, a human GLI-Kruppel-related protein, and relief of repression by adenovirus E1A protein. Cell 67 377-388.

Shi Y, Lee J-S \& Galvin KM 1997 Everything you have ever wanted to know about Yin Yang 1. Biochimica et Biophysica Acta 1332 F49-F66.

Suske G 1999 The Sp-family of transcription factors. Gene $\mathbf{2 3 8}$ 291-300.

Thomas MJ \& Seto E 1999 Unlocking the mechanisms of transcription factor YY1: are chromatin modifying enzymes the key? Gene 236 197-209.

Walowitz JL, Bradley ME, Chen S-J \& Lee T-C 1998 Proteolytic regulation of the zinc finger transcription factor YY1, a repressor of muscle-restricted gene expression. Foumal of Biological Chemistry 273 6656-6661.

White PC 2001 Congenital adrenal hyperplasias. Best Practice and Research. Clinical Endocrinology and Metabolism 15 17-41.

Received in final form 8 March 2004

Accepted 26 March 2004

Made available online as an Accepted Preprint 7 April 2004 